\title{
Cotton-Based Flame-Retardant Textiles: A Review
}

\begin{abstract}
Md. Shahidul Islam and Theo. G. M. van de Ven *
Biodegradable textiles made from cellulose, the most abundant biopolymer, have gained attention from researchers, due to the ease with which cellulose can be chemically modified to introduce multifunctional groups, and because of its renewable and biodegradable nature. One of the most attractive features required for civilian and military applications of textiles is flame-retardancy. This review focuses on various methods employed for the fabrication of cellulose-based flame-retardant cotton textiles along with their developed flame-retardant properties over the last few years. The most common method is to merge N, S, P, and Si-based polymeric, non-polymeric, polymeric/non-polymeric hybrids, inorganic, and organic/inorganic hybrids with cellulose to fabricate flame-retardant cotton textiles. In these studies, cellulose was chemically bonded with the flame-retardants or in some cases, cotton textiles were coated by flameretardants. The flame-retardant properties of the cotton textiles were investigated and determined by various methods, including the limiting oxygen index (LOI), the vertical flame test, thermal gravimetric analysis (TGA), and by cone calorimetry. This review demonstrates the potential of cellulose-based flame-retardant textiles for various applications.
\end{abstract}

Keywords: Cellulose; Cotton textile; Flame-retardancy

Contact information: Department of Chemistry, McGill University, Montreal, QC, Canada; Quebec Centre for Advanced Materials, and Pulp and Paper Research Centre, 3420 University Street, Montreal, QC, Canada; *Corresponding author: theo.vandeven@mcgill.ca

\section{INTRODUCTION}

The textile markets are currently dominated by synthetic polymer fibers such as polyester and nylon, and natural polymer fibers such as cotton and rayon. The cost of cotton fibers has increased due to limited arable land on which it can be grown. Cotton also requires extensive irrigation and use of pesticides. Increasing concerns regarding the environmental impact of non-biodegradable synthetic polymer fibers prepared from nonrenewable sources are the driving force to find suitable alternatives. Biomass contains large quantities of cellulose, which is biodegradable and unusable as food or feed. Therefore, cellulose has become an extremely suitable candidate as a sustainable alternative to natural or synthetic polymer fibers in textile markets. It is estimated that the production of cellulosic textile fibers in 2015 was 5.2 million tons (approximately $5 \%$ of total filament products), which is projected to reach 10 million tons in 2030 (Carmichael 2014).

Textiles play a significant role in the everyday life of human beings. Textiles are primarily made of organic polymers, which are flammable in nature. The annual UK fire statistics demonstrates that most of the fire accidents that occur in houses involve upholstering furniture, bedding, and nightwear (Salmeia et al. 2016). The inclusion of flame-retardants can prevent or delay the appearance of a flame and can reduce the flamespreading rate of the textile (Salmeia et al. 2016; Babu et al. 2020; Dai et al. 2020; Holdsworth et al. 2020; Thi et al. 2020; Xu et al. 2020; Yin et al. 2020). 
The transmission of heat and oxygen can be prevented by a low heat permeable char layer, which is produced from a flame-retardant textile during burning. Nonflammable gases that are produced during the process, such as $\mathrm{H}_{2} \mathrm{O}$ and $\mathrm{CO}_{2}$, assist in diluting the concentration of the flammable gases and minimizing the absorption of heat energy. In principle, non-flammable gases of a flame-retardant textile can resist flames by functioning in condensed and gaseous phases simultaneously during the burning process (Horrocks et al. 2005; Salmeia et al. 2016; Yusuf 2018; Zhang et al. 2019a). A schematic diagram of a possible flame-retardant mechanism for a flame-retardant textile can be seen in Fig. 1.

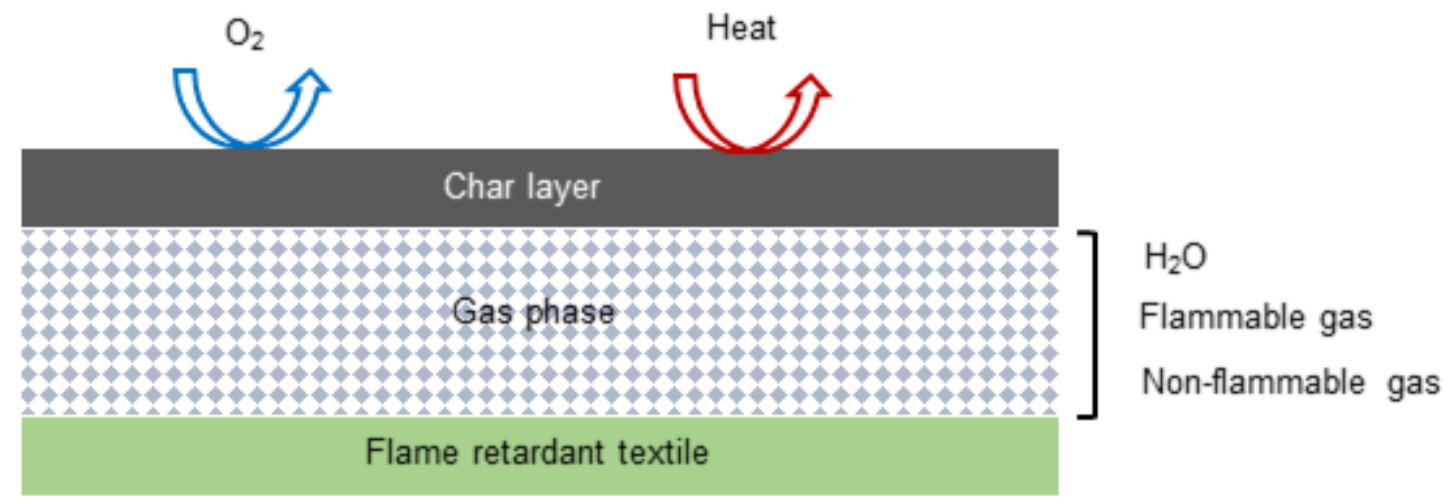

Fig. 1. A schematic representation of the fire-resistant mechanism of flame-retardant textiles

The limiting oxygen index (LOI), the vertical flame test, the thermalgravimetric analysis (TGA), and cone calorimetry are the most common methods employed for investigation of the flame-retardant properties of textiles (Horrocks et al. 1988; Tata et al. 2011; Tata et al. 2012; Lyon et al. 2013; Walters et al. 2015). Several LOI standard methods, such as the ISO standard 4589 and the ASTM standard D2863, are employed to evaluate the flame-retardancy of textiles. Basically, the LOI signifies the least volume percentage of the $\mathrm{O}_{2}$ in a mixture of $\mathrm{O}_{2}$ and $\mathrm{N}_{2}$ that is capable to just sustain flaming combustion of a material, in the same way a candle burns. Literature demonstrates that textiles that have LOI values up to $21 \%$ (by volume) burn quickly, while those with LOI values between $21 \%$ and $25 \%$ burn slowly. Once a the LOI value of a textile goes above $25 \%$, it starts to become flame-retardant (Horrocks et al. 1988).

The ASTM standard D6413 (2015) is used to investigate the flame-retardant properties of textile materials. A test sample is placed vertically above a controlled flame and exposed for a specified period before the flame source is removed. The length of time of the flame exposure to the specimen and the time for which afterglow continues after the flame source has been removed are both recorded. Afterwards, the char length and the visible damage of the test sample after applying a defined tearing force are determined (Zhang et al. 2018b; Kundu et al. 2020).

A thermogravimetric analyzer records the mass of a substance while its temperature changes with time. A conventional thermogravimetric analyzer is made up of a precise balance and a sample holder located inside a furnace in which the temperature is controlled automatically. This instrument starts its measurements at room temperature and then the temperature is increased at a constant rate to cause thermal degradation of the substance used for testing. 
The thermogravimetric analyzer can be operated under a variety of atmospheres, such as, ambient air, vacuum, inert gas, oxidizing/reducing gases, corrosive gases, carburizing gases, vapors of liquids, and at various pressures. (Coats and Redfern 1963; Liu and Yu 2005).

A fire test instrument called a cone calorimeter measures the amount of heat released during the combustion process, which is directly related to the oxygen consumption in the combustion process. The generation of heat is directly proportional to the fire growth rate of a material exposed to an external radiation heat source, which is a measure of the flammability of the material. Usually a sample is exposed to $35 \mathrm{~kW} / \mathrm{m}^{2}$ generated by external flux-forming cone-shaped radiant heaters. However, for more fireretardant materials, the heater frequently is increased to $50 \mathrm{~kW} / \mathrm{m}^{2}$. This calorimeter can measure the heat release rate by the oxygen consumption, the mass loss rate, the smoke production rates, and the $\mathrm{CO}_{2} / \mathrm{CO}$ production rates (Beyler et al. 2017). A low $\mathrm{CO}_{2} / \mathrm{CO}$ ratio implies incomplete burning and is an indication of flame-retardancy.

Cellulose-based textiles, with superior quality and distinctive features, have carved a niche for themselves in the world of fashion. Countries all over the world are involved in developing innovative cellulose-based fabrics. In comparison with synthetic fibers, cellulose fibers, such as cotton and rayon, have important advantages, as they are abundant, biodegradable, and can be recyclable. The number of applications for cellulose-based flame-retardant textiles increases day by day world-wide (Gaan et al. 2011; Horrocks 2013). Flame-retardants textiles are used as protective clothing for people in many chemical industries, as uniforms for fire-fighter, as gear for soldiers and used in many other places, where there is a chance of causing accidents due to contact with flames.

Textiles are made flame-resistant by the inclusion of flame-retardant chemicals. A chemical additive in the fiber or treatment on the fabric is used to provide some level of flame-retardancy. This review will provide information on the different types of flameretardants that can be employed to fabricate cotton-based flame-retardant textiles. Flameretardants that are effective for cotton are likely to be equally effective in rayon, and other cellulose-based materials.

\section{FLAME-RETARDANT PROPERTIES OF NON-TREATED COTTON}

The flame-retardancy efficiency of cotton fabrics treated with flame-retardants can be judged by comparing them with the flame-retardant properties of non-treated cotton. Results for non-treated cotton from various studies are summarized in Table 1.

The cotton fabrics burned completely without any residue formation. The LOI values of the pure cotton ranged from $16 \%$ to $22 \%$, the percentage of the remaining char ranged from $0 \%$ to $16 \%$, the $\left[\mathrm{CO}_{2}\right] /[\mathrm{CO}]$ ratio ranged from 33 to 143 , and the percentage residue as measured by cone calorimetry ranged from $0 \%$ to approximately $7 \%$. These variations are mainly due to the natural variability of cotton and somewhat different test conditions. Flame-retardant cotton should have higher LOI values, more remaining char, a lower $\left[\mathrm{CO}_{2}\right] /[\mathrm{CO}]$ ratio, and higher residues. 
Table 1. Flame-Resistant Ability of Non-Treated Cotton

\begin{tabular}{|c|c|c|c|c|}
\hline \multirow[t]{2}{*}{ LOI (\%) } & \multirow{2}{*}{$\begin{array}{c}\text { Char (\%) at } \\
600^{\circ} \mathrm{C} \text {, from } \\
\text { TGA }\end{array}$} & \multicolumn{2}{|c|}{$\begin{array}{c}\text { Cone Calorimeter } \\
\text { Data }\end{array}$} & \multirow[t]{2}{*}{ References } \\
\hline & & $\begin{array}{c}{\left[\mathrm{CO}_{2}\right] /} \\
{[\mathrm{CO}] \text { Ratio }}\end{array}$ & $\begin{array}{l}\text { Residue } \\
(\%)\end{array}$ & \\
\hline- & $\sim 12$ & 39 & - & (Manfredi et al. 2018a) \\
\hline 18 & 1.2 & - & - & (Taherkhani and Hasanzadeh 2018) \\
\hline- & $\sim 13$ & $\sim 33.2$ & 0 & (Emilitri et al. 2007; Manfredi et al. 2018b) \\
\hline 17.2 & 2.5 & 56.51 & - & (Ling and Guo 2020) \\
\hline 18.4 & $\sim 10$ & $\sim 83$ & 1.32 & (Lu et al. 2018) \\
\hline 17.8 & $\sim 0.8$ & 86.18 & 1.31 & (Feng et al. 2017) \\
\hline$\sim 20$ & $\sim 8$ & 78 & 1.3 & (Zheng et al. 2016) \\
\hline 18.4 & $\sim 10$ & 78 & 1.2 & (Wan et al. 2019) \\
\hline 18.5 & $\sim 9$ & 78 & 6.9 & (Tian et al. 2019) \\
\hline 17.8 & 12 & 77 & 7.5 & (Li et al. 2019) \\
\hline 17.7 & 0 & - & 0 & (Huang et al. 2019) \\
\hline 16 & $\sim 5$ & 113.56 & 0 & (Zhang et al. 2018a) \\
\hline $18.3-21$ & $5-13$ & - & - & $\begin{array}{c}\text { (Yoshioka-Tarver et al. 2012; Sun et al. } \\
\text { 2016; Xu et al. 2017a, 2017b) }\end{array}$ \\
\hline- & 5.8 & 143 & 1 & (Castellano et al. 2019) \\
\hline 18.4 & $\sim 15$ & - & - & (Zhao et al. 2017) \\
\hline- & - & - & - & (Vigo et al. 1973) \\
\hline$\sim 22$ & 6.3 & - & - & (Xie et al. 2013) \\
\hline 18.5 & $\sim 16.3$ & & & (Zhang et al. 2019a) \\
\hline- & 3.3 & - & - & (Ding et al. 2016) \\
\hline- & $\sim 9 \%$ & - & - & (Lin et al. 2019; Yin et al. 2018) \\
\hline 18.6 & 7.5 & - & - & (Lessana et al. 2011) \\
\hline 18.2 & 8 & - & - & (Li et al. 2019) \\
\hline 16.2 & 0 & - & 3.65 & (Zhang et al. 2019a) \\
\hline 18 & - & - & - & (Cheng et al. 2020) \\
\hline
\end{tabular}

\section{FLAME-RETARDANT COTTON FABRICS OBTAINED BY TREATMENT WITH ORGANIC FLAME-RETARDANTS}

Organic polymeric, nonpolymeric, and polymeric/nonpolymeric hybrid materials that are composed of one or more of the elements such as N, S, P, Si, B, or Cl work as flame-retardant materials. These types of materials are currently used to make flameretardant cellulosic textiles.

\section{Cotton Fabrics Treated with Polymeric Flame-Retardants}

Polymers that contain N, S, and P atoms can work as flame-retardant materials for cellulosic textiles, such as cotton or rayon. Organic polymers can work as a flame-retardant due to the presence of one type or all these three types of elements. These atoms can be found in the original polymers or they can be incorporated by chemical modification.

Cotton fabrics treated with $\mathrm{N}$-based organic polymers

Poly(amidoamine) (PAMAM) can be synthesized by a reaction of $\mathrm{N}, \mathrm{N}^{\prime}-$ methylenebis (acrylamide) (MBA) with (4-aminobutyl) guanidine. An aqueous solution of the synthesized PAMAM was added drop-wise to the cotton fabric uniformly, followed by 
drying for $5 \mathrm{~min}$ at $100{ }^{\circ} \mathrm{C}$. The chemical reaction and all the steps for fabricating the PAMAM-treated cotton fabric are presented in Fig. 2 (Manfredi et al. 2018a).

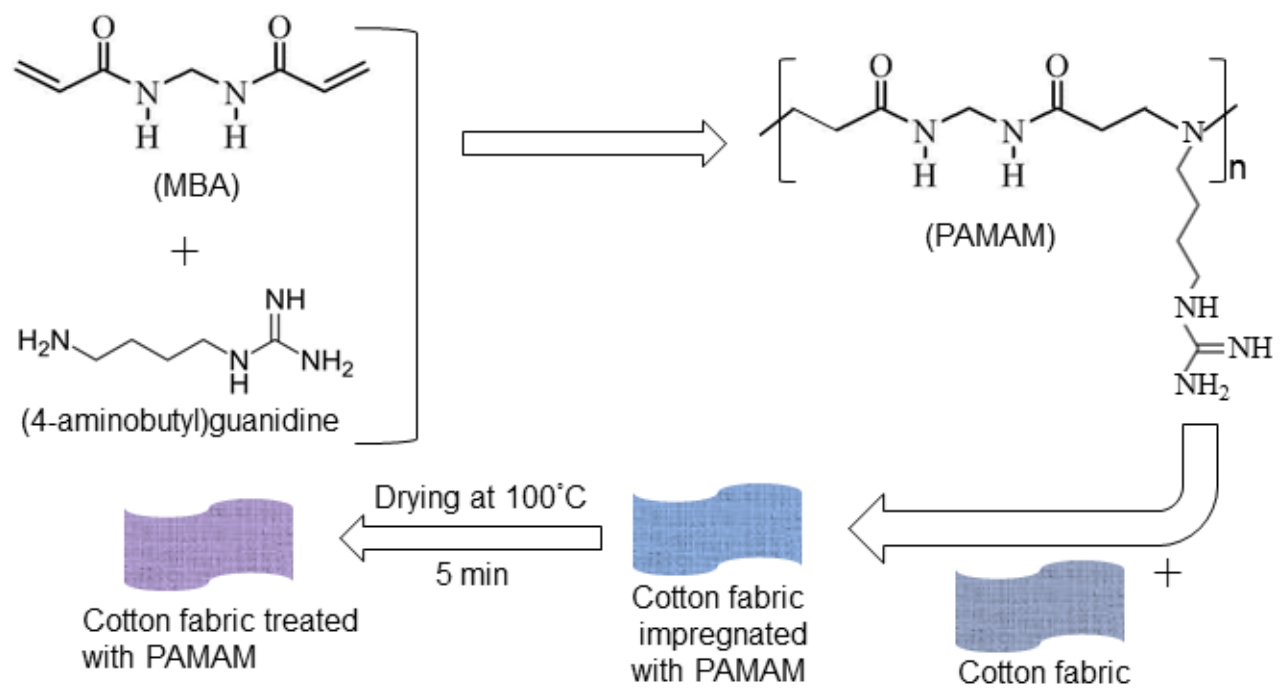

Fig. 2. Steps for fabricating cotton fabric treated with PAMAM (Manfredi et al. 2018a)

Manfredi et al. (2018a) found that the remaining char tested by TGA at $600{ }^{\circ} \mathrm{C}$ and the $\left[\mathrm{CO}_{2}\right] /[\mathrm{CO}]$ ratio tested by cone calorimetry were approximately $12 \%$ and 39 , respectively, for pristine cotton fabric (Table 1). This study also demonstrated that pure cotton fabric burned fully in a short period of time, and no residue was visibly formed in a vertical flame test. However, cotton fabrics impregnated with PAMAM (add-on 19\%) showed a higher char production (approximately $30 \%$, tested by TGA), a lower $\left[\mathrm{CO}_{2}\right] /[\mathrm{CO}]$ ratio (approximately 9, tested by cone calorimetry) than those of pure cotton fabric, and the vertical flame test of the treated fabric resulted in a maximum damaged length (char length) of $2.3 \mathrm{~cm}$ (Table 2) (Manfredi et al. 2018a).

A cotton fabric treated G2-PAMAM (second generation PAMAM dendrimer) is also fire-retardant. It can be produced by first mixing an aqueous solution of citric acid (CA) with sodium hypophosphite (SHP, a catalyst) and dipping a cotton fabric into it, to produce a chemical link between the fabric and the CA. This chemical link was produced by the chemical reaction between the $-\mathrm{OH}$ groups of the fabric and the $-\mathrm{COOH}$ groups of the CA under heating for $4 \mathrm{~min}$ at $160{ }^{\circ} \mathrm{C}$. The cotton fabric chemically linked with the CA was added to a second-generation poly(amidoamine) (G2-PAMAM) dendrimer to allow the chemical reaction between these two chemicals. Basically, amine groups $\left(-\mathrm{NH}_{2}\right)$ of the G2-PAMAM reacted with carboxyl groups $(-\mathrm{COOH})$ of the $\mathrm{CA}$-treated cotton fabric under heating for $4 \mathrm{~min}$ at $160{ }^{\circ} \mathrm{C}$ to form amide bonds. The chemical reactions for the entire process are exhibited in Fig. 3. (Taherkhani and Hasanzadeh 2018).

The flame-retardant properties of cotton fabric covalently bonded with G2PAMAM through CA (as a crosslinker) were also studied by Taherkhani and Hasanzadeh (2018). The LOI and the remaining char, tested via TGA at $600{ }^{\circ} \mathrm{C}$, were approximately $23 \%$ and $25.1 \%$, respectively, of the treated fabric. These values were lower than the control fabric, which had an LOI of $18 \%$ and a remaining char at $600{ }^{\circ} \mathrm{C}$ tested via TGA of $1.2 \%$ ) (Tables 1 and 2). A char length of only $0.32 \mathrm{~cm}$ was obtained for the treated fabric, while the control fabric burned completely as was shown by the vertical flame test 
(Tables 1 and 2). The inclusion of nitrogen-containing PAMAM and G2-PAMAM resulted in excellent flame-retardancy of the treated fabrics.

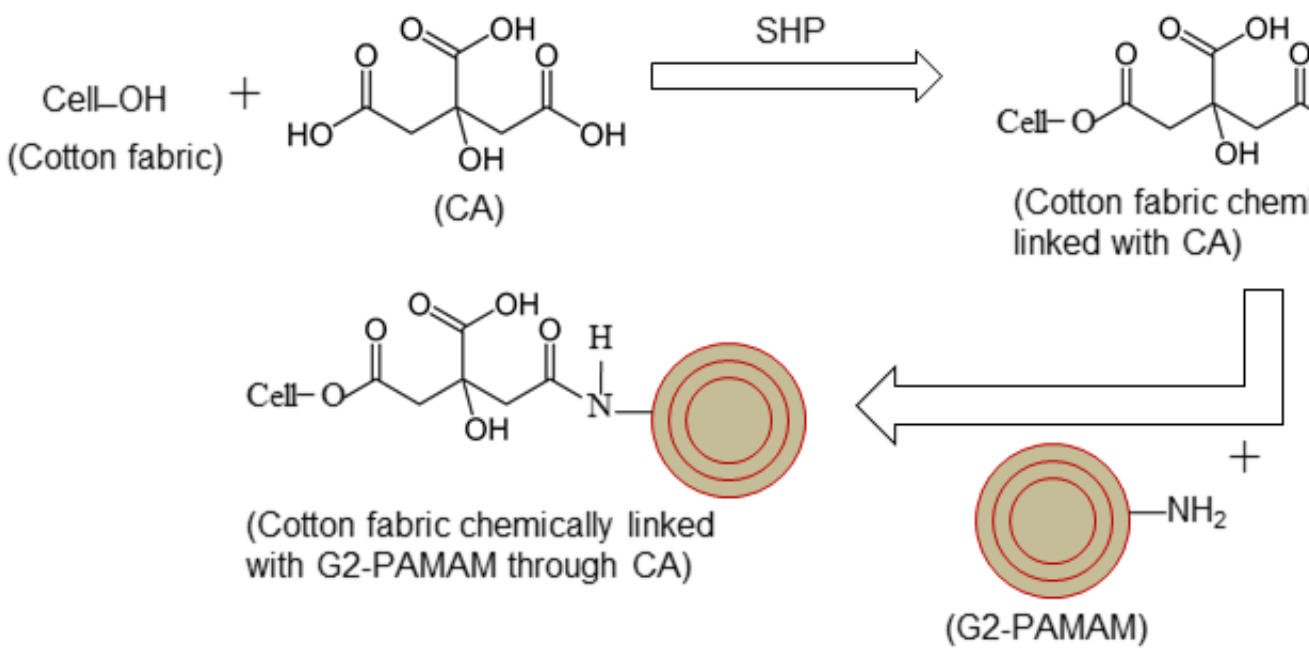

Fig. 3. Chemical reactions for fabricating cotton fabric chemically linked with through $C A$ (Taherkhani and Hasanzadeh 2018)

Cotton fabrics treated with $N$, S-based organic polymers

Cotton fabrics treated with polyamidoamine containing disulfide-groups in the main chain (SS-PAMAM), prepared by Michael polyaddition of 2,2-bis(acrylamido) acetic acid (BAAA) with L-cystine were shown to have flame-retardant properties (Emilitri et al. 2007; Manfredi et al. 2018b). Double-bonded carbon of BAAA reacted with the $-\mathrm{NH}_{2}$ group of L-cystine to produce SS-PAMAM. An aqueous solution of the synthesized SSPAMAM was added to the cotton fabric, after which it was dried for $10 \mathrm{~min}$ at $100{ }^{\circ} \mathrm{C}$.

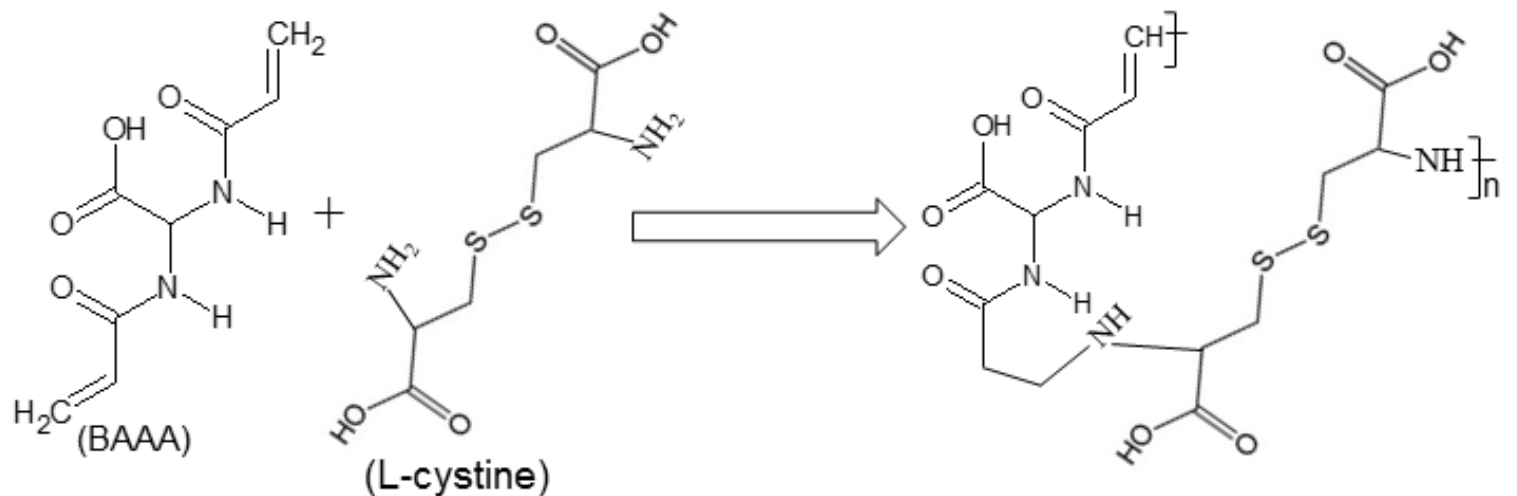

(SS-PAMAM)

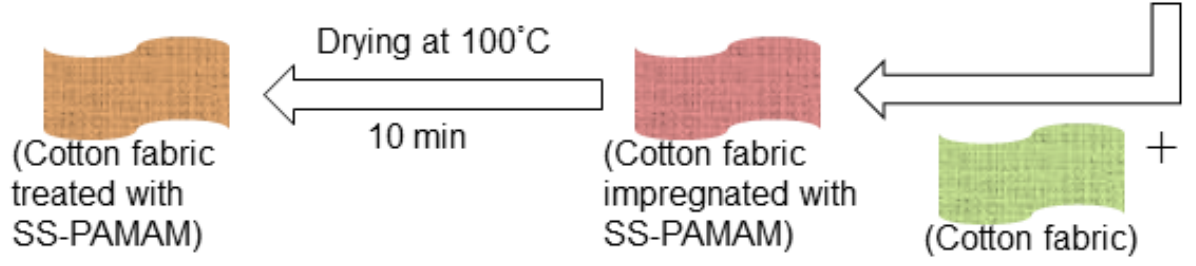

Fig. 4. Steps for fabricating cotton fabric treated with SS-PAMAM (Emilitri et al. 2007; Manfredi et al. 2018b) 
The chemical reaction and all the steps for fabricating the SS-PAMAM treated cotton fabric are exhibited in Fig. 4. The remaining char at $600{ }^{\circ} \mathrm{C}$ (tested via TGA), the $\left[\mathrm{CO}_{2}\right] /[\mathrm{CO}]$, and the residue (investigated by cone calorimetry) were approximately $13 \%$, 33.2 , and $0 \%$, respectively. The non-treated fabric burned completely in a very short time without forming any residue (Table 1) (Emilitri et al. 2007; Manfredi et al. 2018b). An increase in the flame-retardancy was demonstrated by the char formation (24\% by TGA and $5.5 \%$ by cone calorimetry), by the $\left[\mathrm{CO}_{2}\right] /[\mathrm{CO}]$ ratio (approximately 30.8 ) and by the vertical flame test (maximum char length $0.7 \mathrm{~cm}$ ). The flame-retardancy was caused by the incorporation of nitrogen and disulfide containing PAMAM (SS-PAMAM) (add-on 12\%) into the cotton fabric (Table 2).

\section{Cotton fabrics treated with P-based organic polymers}

Mixing a cotton fabric with HBPOPN, the cationic $\mathrm{NH}_{4}{ }^{+}$ions of which reacted with $-\mathrm{OH}$ groups of cellulose, renders it flame-retardant. This reaction is catalyzed by dicyandiamide. The HBPOPN is produced by mixing a hyperbranched polymer (HBP) with phosphoric acid $\left(\mathrm{H}_{3} \mathrm{PO}_{4}\right)$ to obtain the phosphate esterification product of $\mathrm{HBP}$ (called HBPOP), which reacted with urea $\left(\mathrm{H}_{2} \mathrm{~N}-\mathrm{CO}-\mathrm{NH}_{2}\right)$ to produce the ammonium salt of HBPOP (called HBPOPN). The chemical reactions of this entire process are shown in Fig. 5 (Ling and Guo 2020).

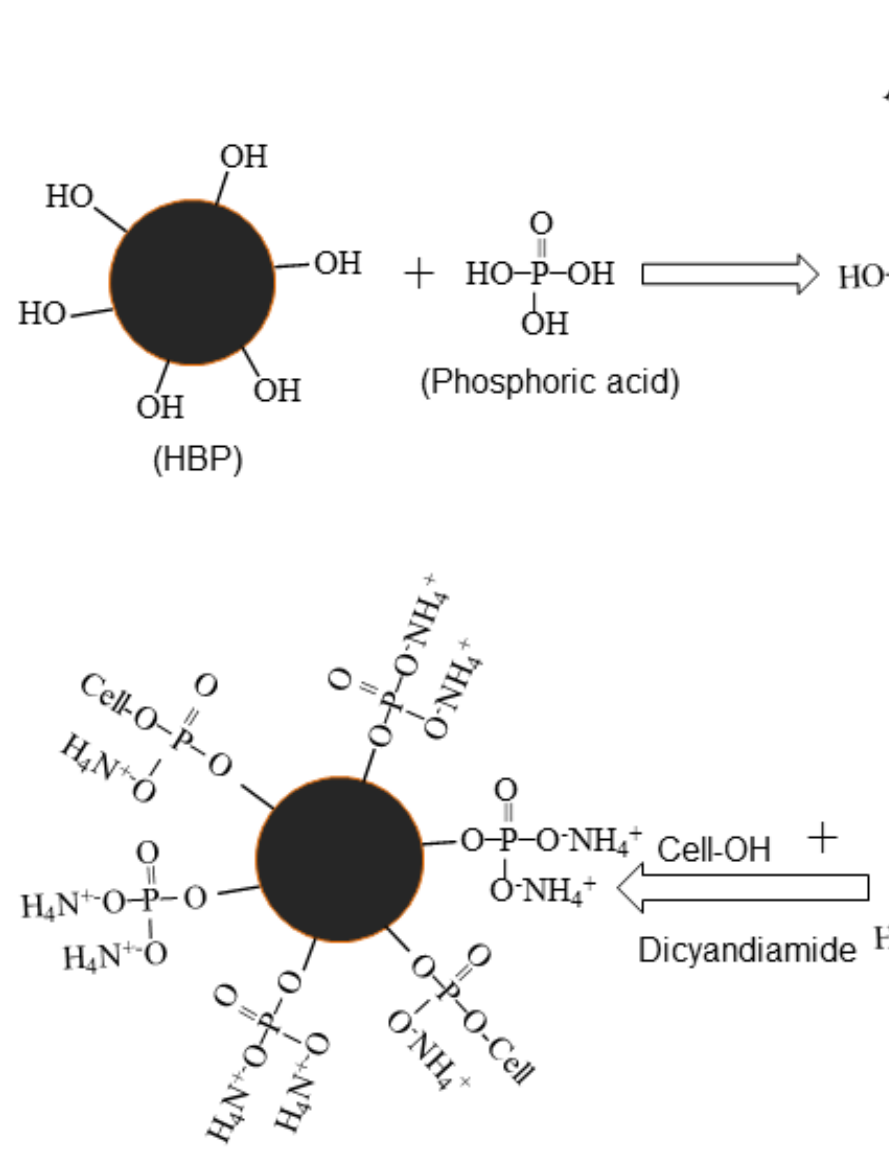

(Cotton fabric modified by HBPOPN)
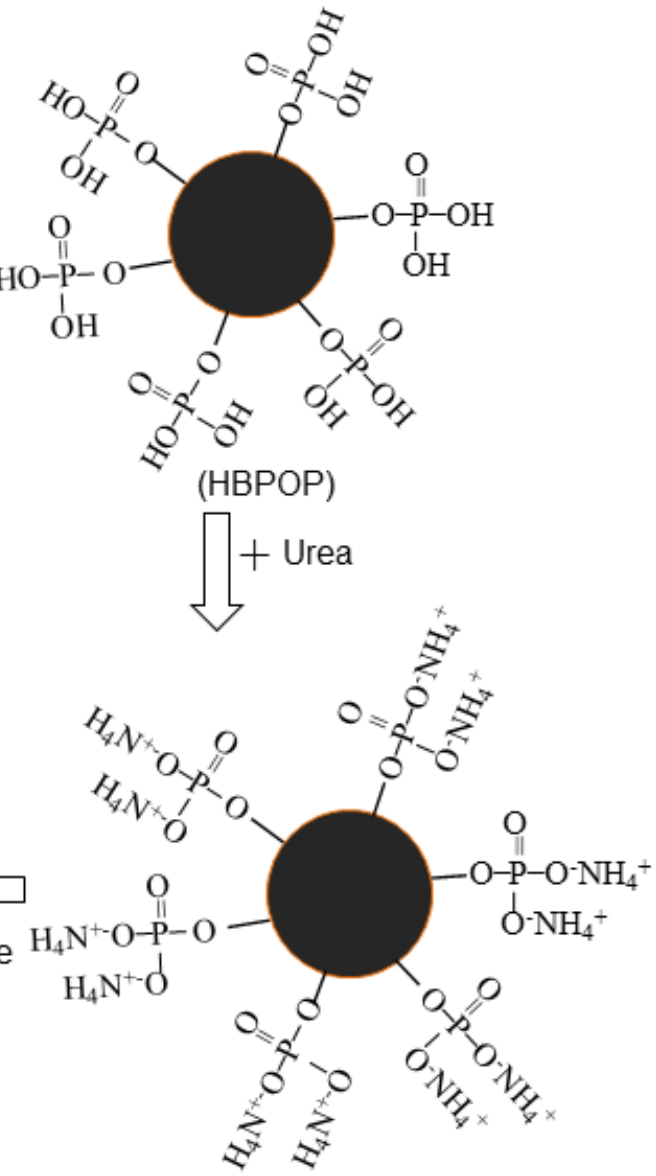

(HBPOPN)

Fig. 5. Chemical reactions for fabricating cotton fabric (Cell-OH) modified by HBPOPN (Ling and Guo 2020) 
In principle, the HBPOPN can link to 12 glucose units of cellulose. However, the cotton yarn made from cellulose chains is porous, with a pore size of the order of microns, which is much larger than the size of a HBPOPN macromolecule. Therefore, the HBPOPN usually links to only one cellulose molecule, except for chain crossings or chains in close proximity, in which case it is able to bridge two cellulose chains. The inclusion of phosphorus-containing HBPOPN increased the flame-retardancy of the cotton significantly. Ling and Guo (2020) showed that the incorporation of $28.1 \%$ HBPOPN enhanced the LOI (42\%) and char formation (approximately 35\%, tested by TGA at 600 ${ }^{\circ} \mathrm{C}$ ), decreased the $\left[\mathrm{CO}_{2}\right] /[\mathrm{CO}]$ ratio (3.11), and gave a maximum char length of $5.6 \mathrm{~cm}$ for the cotton fabric. The untreated cotton fabric had a lower LOI (17.2\%) and TGA char formation $\left(2.5 \%\right.$ at $600{ }^{\circ} \mathrm{C}$ ) (Tables 1 and 2). The non-treated cotton fabric also showed a higher $\left[\mathrm{CO}_{2}\right] /[\mathrm{CO}]$ ratio (56.5) and burned completely in the vertical flame test (Table 1).

\section{Cotton Fabrics Treated with Non-polymeric Flame Retardants}

Non-polymeric organic compounds that contain the elements $\mathrm{N}, \mathrm{P}, \mathrm{Si}, \mathrm{B}$, or $\mathrm{Cl}$ can work as flame-retardant materials for cellulosic textiles. These types of organic compounds can work as flame-retardants due to the presence of one type or more than one type of these five categories of elements. They can be found in the original organic compound or they can be incorporated by chemical modification.

\section{Cotton fabrics treated with P-based non-polymeric organic compounds}

An example of a non-polymeric organic compound that contains phosphor atoms is the ammonium salt of 1-hydroxyethylidene-1,1-diphosphonic acid (AHEDPA). It is produced by mixing 1-hydroxyethylidene-1,1-diphosphonic acid (HEDPA) with urea. To render the cotton flame-resistant, it was treated with AHEDPA. The cationic $\mathrm{NH}_{4}{ }^{+}$ions of the AHEDPA reacted with the $\mathrm{OH}$ groups of the cellulose to produce a covalent bond between them. This reaction was catalyzed by dicyandiamide. The chemical reactions of this process are shown in Fig. 6 (Lu et al. 2018).
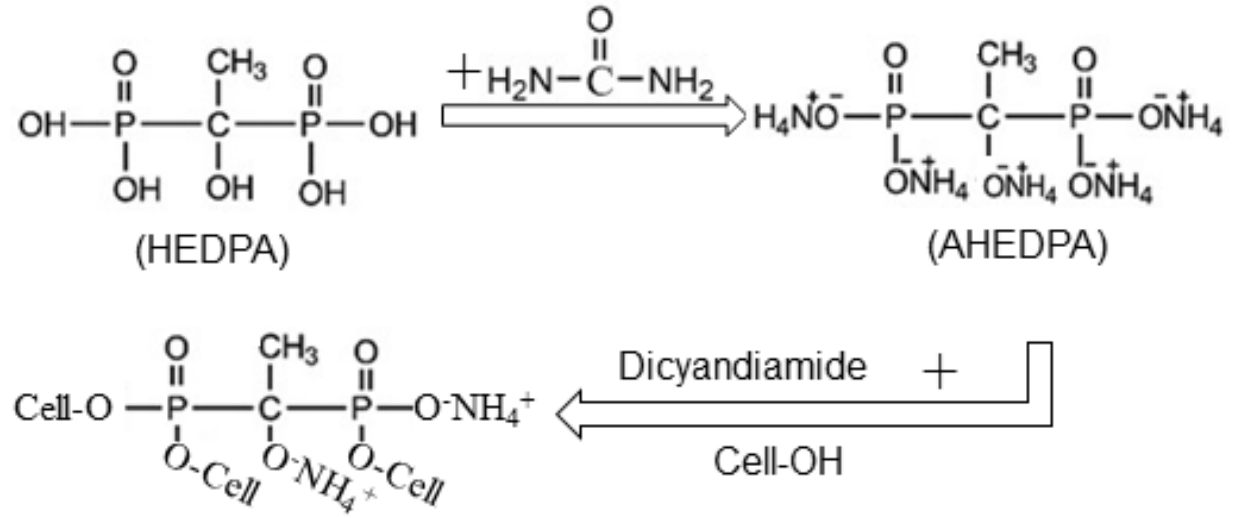

\section{(Cotton fabric treated with AHEDPA)}

Fig. 6. Chemical reactions for fabricating cotton fabric treated with AHEDPA (Lu et al. 2018)

Another example is ammonium phytate (APA), produced by mixing phytic acid (PA) with urea. As seen in cotton, mixed with APA, the cationic $\mathrm{NH}_{4}{ }^{+}$ions of the APA reacted with the $-\mathrm{OH}$ groups of the cellulose to produce a flame-retardant cotton fabric. This reaction was also catalyzed by dicyandiamide. The chemical reactions of this process are shown in Fig. 7 (Feng et al. 2017). The flame-retardant properties of the cotton fabric 
were developed due to covalent linkages of the cellulose chains with phosphorous containing non-polymeric compounds, such as AHEDPA and APA. By incorporating $20.11 \%$ AHEDPA, a significant increase in the flame-retardancy was achieved in which the LOI, the TGA char formation at $600{ }^{\circ} \mathrm{C}$, and the cone calorimeter residue increased from $18.4 \%$ to $41.5 \%$, approximately $10 \%$ to approximately $45 \%$, and $1.3 \%$ to $38.9 \%$, respectively, as reported by Lu et al. (2018) (Tables 1 and 2). In that study, it was also found that the $\left[\mathrm{CO}_{2}\right] /[\mathrm{CO}]$ ratio decreased from approximately 83 to 3.77 , and for the treated fabric a damaged length of only $5.3 \mathrm{~cm}$ was obtained (Tables 1 and 2). Feng et al. investigated APA-treated textile and found that the LOI, the remaining char at $600{ }^{\circ} \mathrm{C}$ (tested by TGA), and the $\left[\mathrm{CO}_{2}\right] /[\mathrm{CO}]$ ratio and residue (tested by cone calorimetry) were $17.8 \%$, approximately $0.8 \%$, and approximately 86.18 and $1.31 \%$, respectively, for the control fabric, which burned completely with no residue (Table 1). In contrast, the LOI, the remaining char at $600{ }^{\circ} \mathrm{C}$ (tested by TGA), and the $\left[\mathrm{CO}_{2}\right] /[\mathrm{CO}]$ ratio and residue (tested by cone calorimeter) were $36.1 \%$, approximately $40 \%$, and 3.05 and $36.24 \%$, respectively, for the fabric treated with APA (add-on 14.49\%) (Table 2). Similar results were obtained those of the AHEDPA-treated samples (Feng et al. 2017; Lu et al. 2018). This treated fabric also promptly self-extinguished after ignition, and the maximum damaged length (char length) was $3.5 \mathrm{~cm}$ (Table 2).<smiles>NC(=O)CCCCCCCCCCCCCCC(N)=O</smiles>

(PA)<smiles></smiles>

(APA)

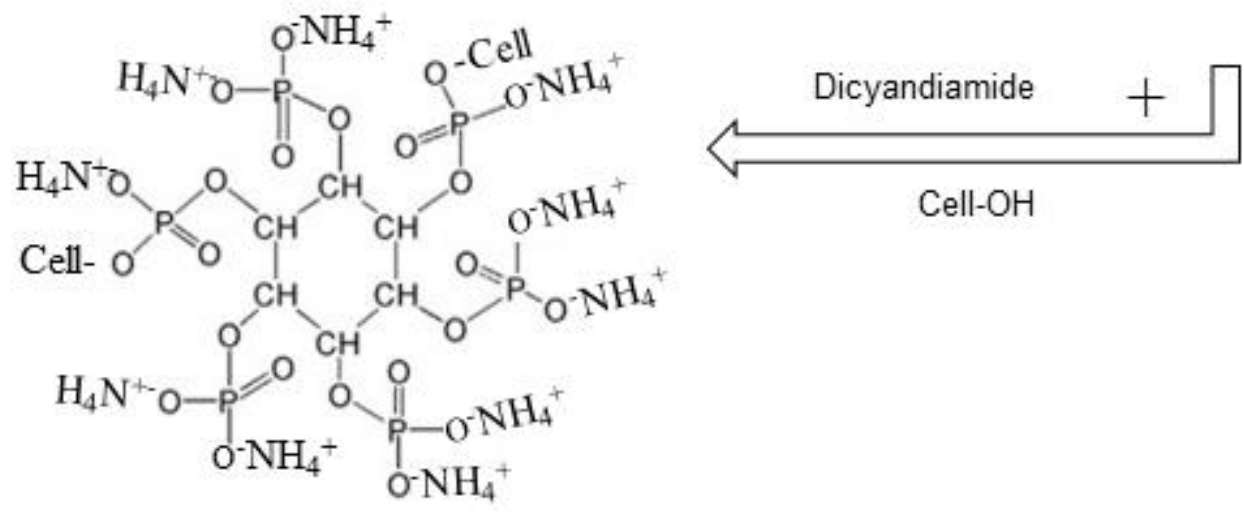

(Cotton fabric treated with APA)

Fig. 7. Chemical reactions for fabricating cotton fabric treated with APA (Feng et al. 2017) 
Cotton fabrics treated with N, P-based non-polymeric organic compounds

An example of a nitrogen containing compound is the ammonium salt of ethylenediamine tetramethylenephosphonic acid (AEDTMPA). The AEDTMPA is produced by reacting ethylenediamine tetramethylenephosphonic acid (EDTMPA), prepared from the reaction that occurs among the reactants ethylenediamine, formaldehyde, and phosphorous acid $\left(\mathrm{H}_{3} \mathrm{PO}_{3}\right)$, with urea. After adding a cotton fabric, the $-\mathrm{OH}$ groups of the cellulose molecules reacted with the phosphonic groups in the AEDTMPA to form $\mathrm{P}-\mathrm{O}-\mathrm{C}$ covalent bonds. The chemical reactions of the entire process are presented in Fig. 8 (Zheng et al. 2016).

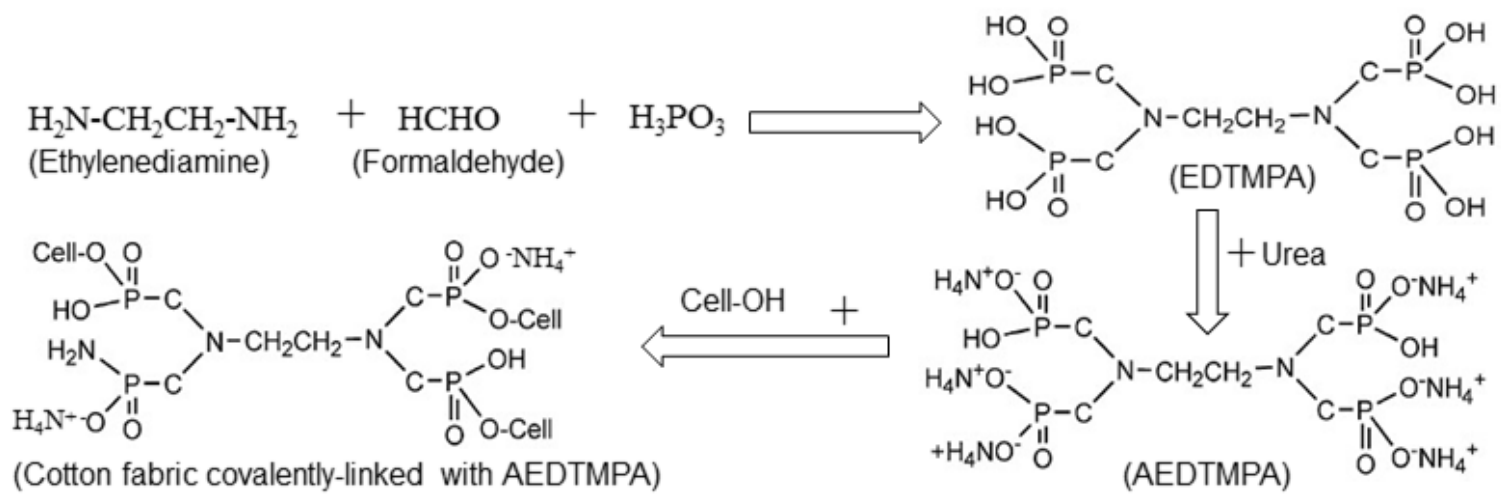

Fig. 8. Chemical reactions for fabricating cotton fabric treated with AEDTMPA (Zheng et al. 2016).

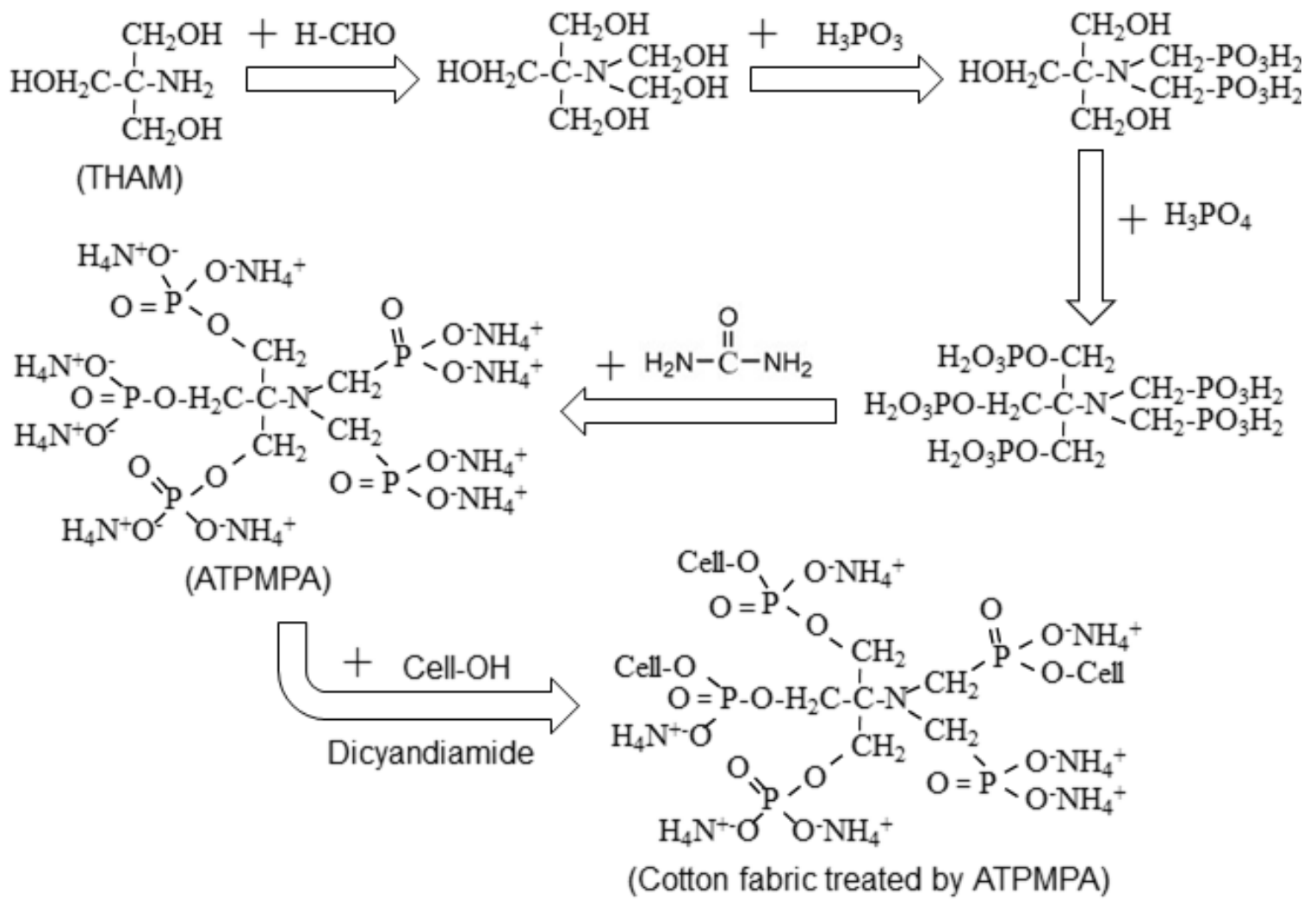

Fig. 9. Chemical reactions for fabricating cotton fabric treated with ATPMPA (Wan et al. 2019) 
A second example is the ammonium salt of tris-(hydroxymethyl)- aminomethane-penta (methyl phosphonic acid) (ATPMPA), which was prepared by mixing tris-(hydroxymethyl)-aminomethane (THAM) with formaldehyde ( $\mathrm{H}-\mathrm{CHO}), \mathrm{H}_{3} \mathrm{PO}_{3}$, and $\mathrm{H}_{3} \mathrm{PO}_{4}$ to obtain the phosphate esterification product of THAM, which reacted with urea $\left(\mathrm{H}_{2} \mathrm{~N}-\mathrm{CO}-\mathrm{NH}_{2}\right)$ to produce ATPMPA. When added to cotton, the $\mathrm{NH}_{4}{ }^{+}$cations of the ATPMPA reacted with the $-\mathrm{OH}$ groups of the cellulose to produce a flame-retardant cotton fabric. This reaction was catalyzed by dicyandiamide. The chemical reactions of this entire process are shown in Fig. 9 (Wan et al. 2019).

A third example is the ammonium salt of tetraethylenepentamine heptamethylphosphonate (ATEPAHP), prepared from the reaction occurring among the reactants tetraethylenepentamine (TEPA), formaldehyde, and $\mathrm{H}_{3} \mathrm{PO}_{3}$. The produced TEPAHP was then mixed with urea to produce ATEPAHP. When added to cotton, the -OH groups of the cellulose react with the phosphonate groups of the ATEPAHP to form $\mathrm{P}-\mathrm{O}-\mathrm{C}$ covalent bonds, a reaction catalyzed by dicyanodiamide. The chemical reactions of the entire process are presented in Fig. 10 (Tian et al. 2019).

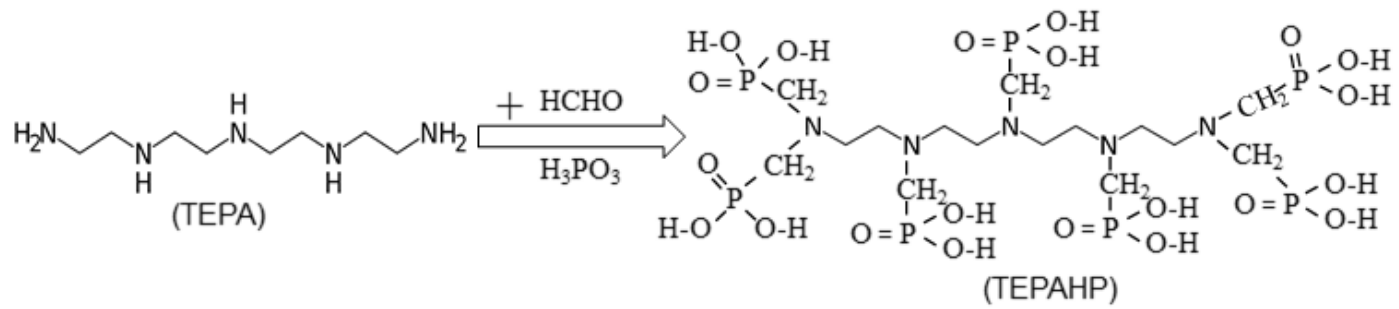

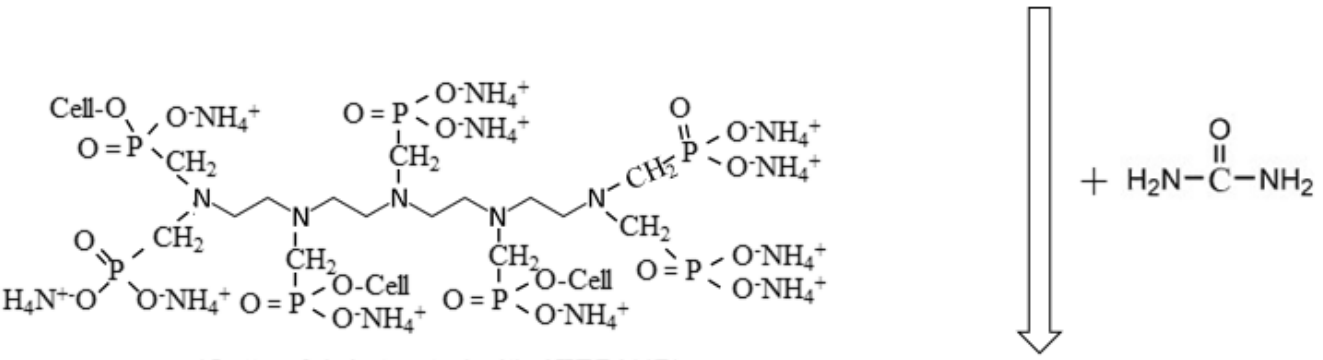

(Cotton fabric treated with ATEPAHP)

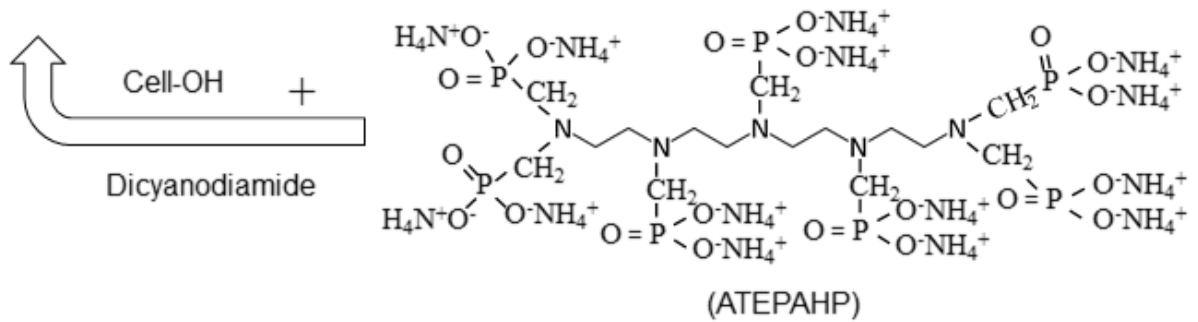

Fig. 10. Chemical reactions for fabricating cotton fabric treated by ATEPAHP (Tian et al. 2019)

In a fourth example, diethanolamine (DEA) was mixed with formaldehyde (H$\mathrm{CHO}$ ), $\mathrm{H}_{3} \mathrm{PO}_{3}$, and $\mathrm{H}_{3} \mathrm{PO}_{4}$ to obtain the phosphate esterification product of DEA, which reacted with urea $\left(\mathrm{H}_{2} \mathrm{~N}-\mathrm{CO}-\mathrm{NH}_{2}\right)$ to produce the ammonium salt of cholamine (methylenephosphonic acid) ethylene-organic phosphate acid (ACMPEP). Finally, cotton fabric was treated with ACMPEP, which resulted in reaction of $\mathrm{NH}_{4}{ }^{+}$ions with the $-\mathrm{OH}$ groups of the cellulose to produce a flame-retardant cotton fabric. This reaction was catalyzed by dicyandiamide. The chemical reactions of this entire process are shown in Fig. 11 (Li et al. 2019). 
<smiles>O=C(C=CC(O)COCCNCCO)OCCO</smiles>

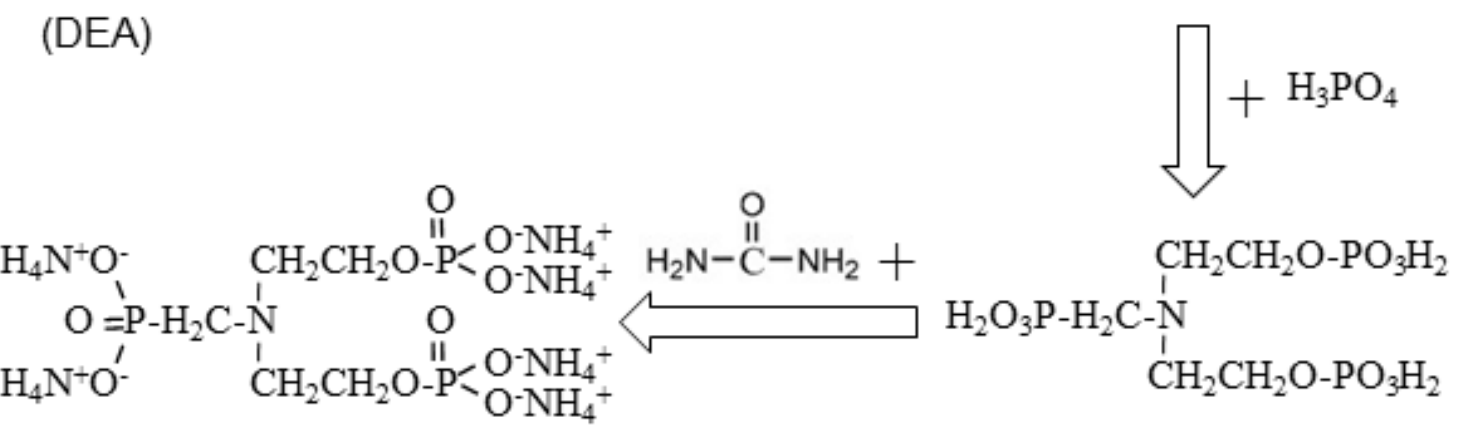
(ACMPEP)

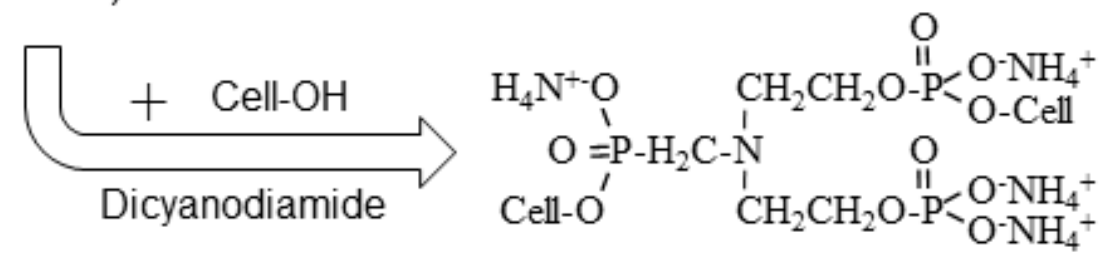

(Cotton fabric treated by ACMPEP)

Fig. 11. Chemical reactions for fabricating cotton fabric treated by ACMPEP (Li et al. 2019)

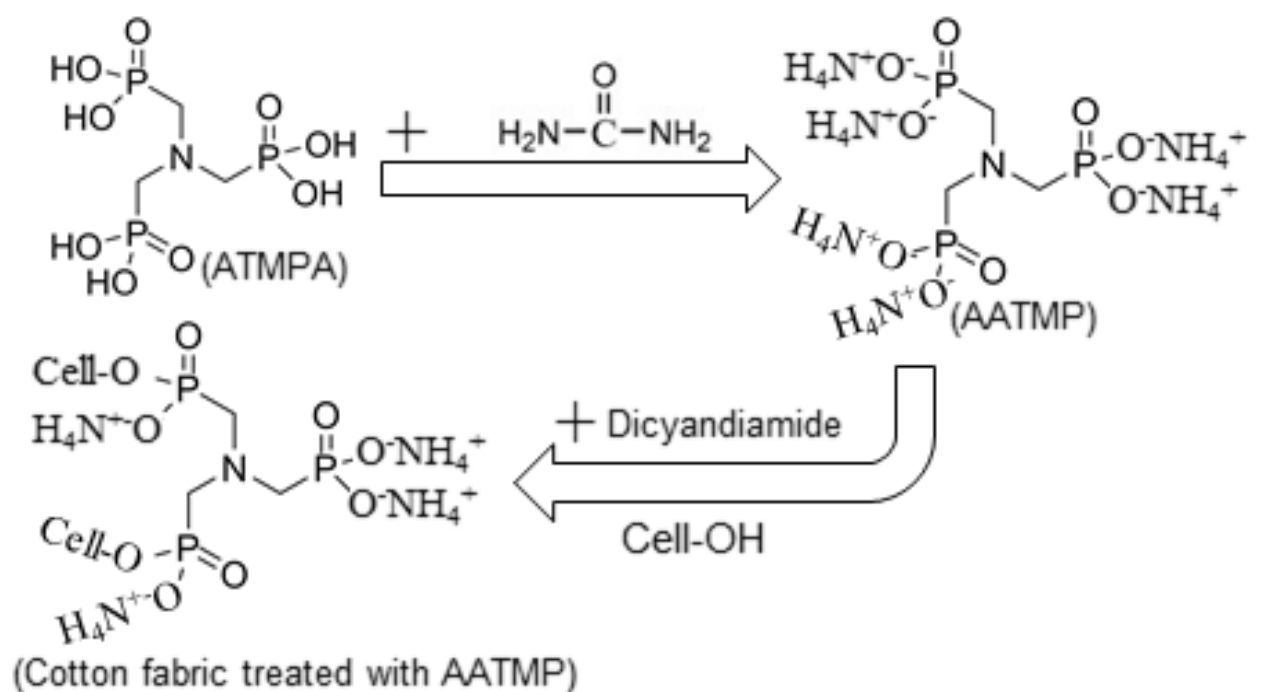

Fig. 12. Chemical reactions for fabricating cotton fabric treated by AATMP (Huang et al. 2019)

A fifth example is ammonium amino trimethylene phosphonate (AATMP), produced from amino trimethylene phosphonic acid (ATMPA) mixed with urea. When mixing a cotton fabric with AATMP, the $\mathrm{NH}_{4}{ }^{+}$cations reacted with the $-\mathrm{OH}$ groups of the cellulose to produce a flame-retardant cotton fabric. As in previous cases, this reaction was catalyzed by dicyandiamide. The chemical reactions of this entire process are presented in Fig. 12 (Huang et al. 2019).

A final example of a nitrogen-containing compound is the ammonium salt of melamine hexa(methylphosphonic acid (AMHMPA), synthesized by the reaction between 
urea and melamine hexa(methylphosphonic acid) (MHMPA), obtained by a reaction between melamine (MA), formaldehyde ( $\mathrm{H}-\mathrm{CHO})$, and $\mathrm{H}_{3} \mathrm{PO}_{3}$. After adding a cotton fabric, $\mathrm{NH}_{4}{ }^{+}$cations of AMHMPA react with -OH groups of cellulose to produce a flameretardant cotton fabric. This reaction was also catalyzed by dicyandiamide. The chemical reactions of this entire process are presented in Fig. 13 (Zhang et al. 2018a).

An example of a compound containing both nitrogen and phosphor atoms is AEDTMPA (ammonium salt of ethylenediamine tetramethylenephosphonic acid). Zheng et al. (2016) demonstrated that the inclusion of N, P-based AEDTMPA into cotton increased its flame-retardancy. The LOI, the TGA char formation, and the cone calorimeter residue increased from approximately $20 \%$ to $43.6 \%$, approximately $8 \%$ to approximately $43.4 \%$ (at $600{ }^{\circ} \mathrm{C}$ ) and $1.3 \%$ to $42.5 \%$, respectively (Tables 1 and 2). Pristine cellulosic textiles burned completely while the AEDTMPA-treated textiles had a damaged length of just $3.5 \mathrm{~cm}$ obtained by the vertical flame test. The $\left[\mathrm{CO}_{2}\right] /[\mathrm{CO}]$ ratio decreased from 78 to 2.1 after treatment.

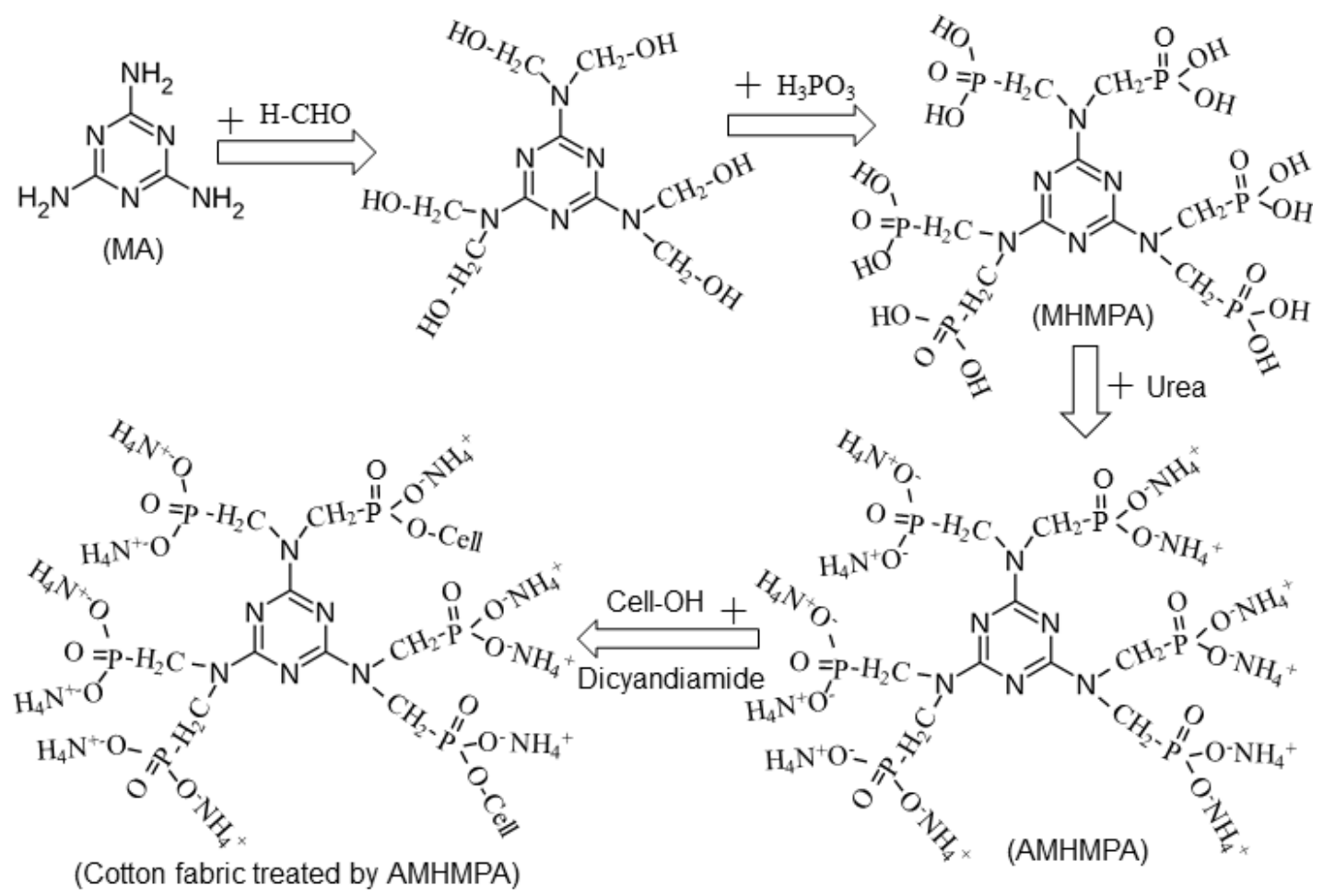

Fig. 13. Chemical reactions for fabricating cotton fabric treated by AMHMPA (Zhang et al. 2018a)

Another example of a fire-retardant containing both $\mathrm{N}$ and $\mathrm{P}$ atoms is ATPMPA (ammonium salt of tris-(hydroxymethyl)-aminomethane-penta (methyl phosphonic acid)). Wan et al. (2019) showed that although the pure cotton fabric burned fully, the inclusion of $26.13 \%$ of ATPMPA decreased the damage length significantly to $2.5 \mathrm{~cm}$, as determined by the vertical flame test (Tables 1 and 2). The LOI, the TGA char formation (at $600{ }^{\circ} \mathrm{C}$ ), and the cone calorimeter residue increased from $18.4 \%$ to $43.6 \%$, approximately $10 \%$ to $38 \%$, and $1.2 \%$ to $30.8 \%$, respectively, and the $\left[\mathrm{CO}_{2}\right] /[\mathrm{CO}]$ ratio decreased from 78 to 28.5 after the incorporation of the N, P-based ATPMPA flame-retardant. (Tables 1 and 2).

Other studies examined the flame-retardant properties of cellulose textiles by incorporating the N-P-based flame retardants ATEPAHP (ammonium salt of tetraethylene 
pentaamine heptamethylphosphonate), ACMPEP (ammonium salt of cholamine (methylene phosphonic acid) ethylene-organic phosphate acid), AATMP (ammonium amino trimethylene phosphonate), and AMHMPA (ammonium salt of melamine hexa(methylphosphonic acid), respectively (Zhang et al. 2018a; Huang et al. 2019; Li et al. 2019; Tian et al. 2019). The vertical flame tests demonstrated that the pristine cellulose textiles burned fully, but damage lengths of $4.8 \mathrm{~cm}, 3.8 \mathrm{~cm}, 3.0 \mathrm{~cm}$, and $5.3 \mathrm{~cm}$ were obtained for the cellulose textiles treated with ATEPAHP, ACMPEP, AATMP, and AMHMPA, respectively (Tables 1 and 2). In each study, the LOI, the TGA char formation (at $600{ }^{\circ} \mathrm{C}$ ) and the residue studied by cone calorimeter increased, and the $\left[\mathrm{CO}_{2}\right] /[\mathrm{CO}]$ ratio decreased (Tables 1 and 2). This demonstrates that these compounds have excellent fireretardant properties.

Cotton fabrics treated with $N, P$, Si-based non-polymeric organic compounds

Flame-retardant cotton can be obtained in a two-step process, in which the cotton is first treated with 3-mercaptopropyltriethoxysilane (MPTES) and subsequently with dimethyl-[1,3,5-(3,5-triacryloylhexahydro)triazinyl]-3-oxopropylphosphonate (DHTP). In the reaction with MPTES, a covalent link is formed between cellulose and MPTES through an $\mathrm{O}-\mathrm{Si}$ linkage that results from the reaction between an oxyethyl group on one end of MPTES and a hydroxyl group of the fiber surface (Sun et al. 2016). In the reaction with DHTP, a thiol group of the MPTES-treated cotton fabric reacted with DHTP to produce a non-halogenated organophosphorous based flame-retardant cotton fabric (Yoshioka-Tarver et al. 2012; Xu et al. 2017). The protocol for the synthesis of DHTP is described elsewhere (Weil 1974; Weil 1975; Yoshioka-Tarver et al. 2012; Xu et al. 2017a). The reactions for fabricating the DHTP-based flame-retardant cotton fabric are shown in Fig. 14.

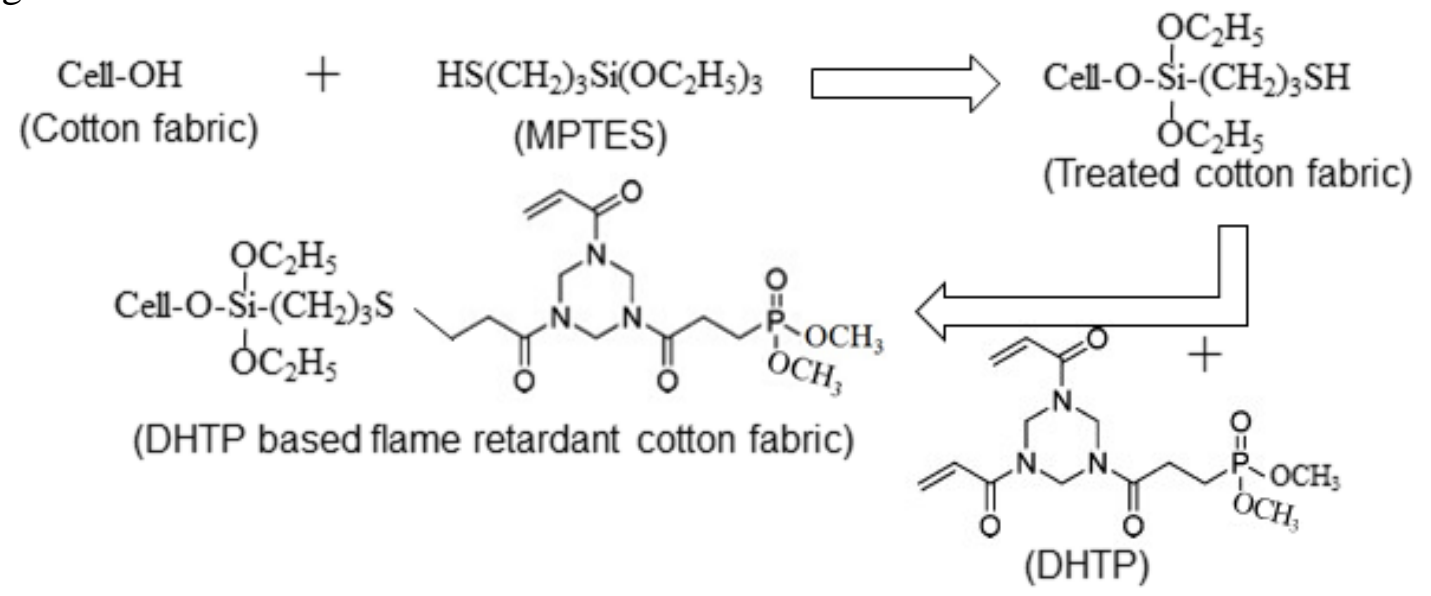

Fig. 14. Chemical reactions for fabricating DHTP based flame retardant cotton fabric (YoshiokaTarver et al. 2012; Sun et al. 2016; Xu et al. 2017a,b)

Another example of this class is (3-glycidyloxypropyl triethoxysilane modified N(phosphonomethyl) iminodiacetic acid (PGPTES). Cotton can be rendered flame-resistant by immersing it in a PGPTES solution, followed by drying at $90{ }^{\circ} \mathrm{C}$ for $5 \mathrm{~min}$ followed by curing at $170{ }^{\circ} \mathrm{C}$ for $5 \mathrm{~min}$. The entire process for the fabrication of the cotton fabric coated by a PGPTES solution is shown schematically in Fig. 15. 


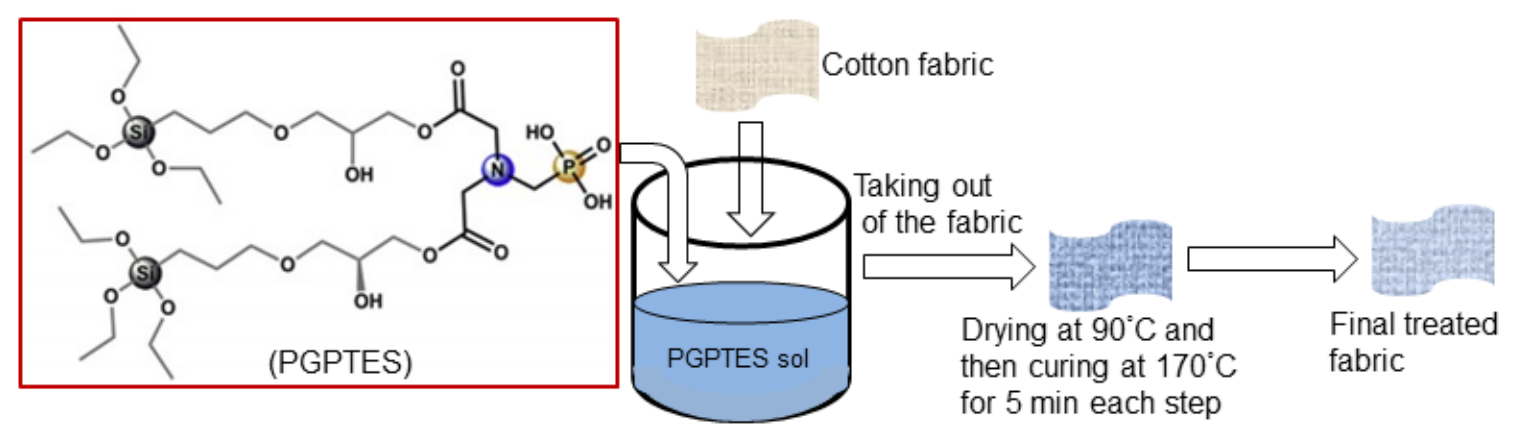

Fig. 15. Schematics of fabrication of cotton fabric coated by PGPTES (Castellano et al. 2019)

Another example is the H-DPTA, obtained by the hydrolysis of $\mathrm{N}$ (diphenylphosphino)-1,1-diphenyl-N-(3-(triethoxysilyl)propyl) phosphinamine (DPTA), produced by the reaction of 3-triethoxysilylpropylamine with chlorodiphenylphosphine $\left(\mathrm{Ph}{ }_{2} \mathrm{PCl}\right)$. The chemical reactions of this process are shown in Fig. 16 (Zhao et al. 2017).

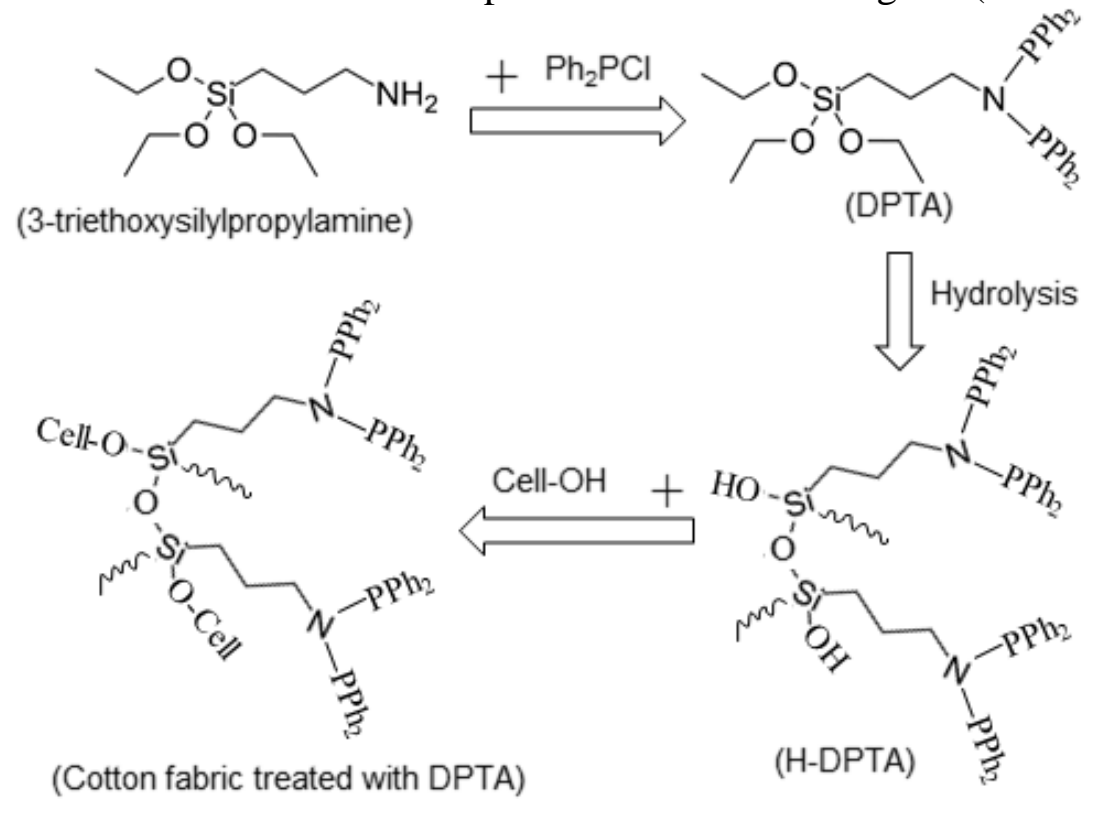

Fig. 16. Chemical reactions for fabricating cotton fabric treated by H-DPTA (Zhao et al. 2017)

Finally, DHTP (dimethyl-[1,3,5-(3,5-triacryloylhexahydro)triazinyl]-3-oxopropyl phosphonate), PGPTES ((3-glycidyloxypropyl triethoxysilane modified N-(phosphonomethyl) iminodiacetic acid), and DPTA (N-(diphenylphosphino)-1,1-diphenyl-N-(3(triethoxysilyl) propyl) phosphinamine) are all N, P, and Si-based non-polymeric organic compounds, which can enhance the flame-retardancy of cotton fabrics. Studies have examined the flame-retardancy of cotton fabric covalently-linked with DHTP, and found that the LOI and the TGA char formation (at $600{ }^{\circ} \mathrm{C}$ ) increased from $26.1 \%$ to $34 \%$ and $31.2 \%$ to $43 \%$, respectively. For pure cotton fabrics the LOI was between $18.3 \%$ and $21 \%$ and the TGA char formation was 5\% to 13\%. (Tables 1 and 2) (Yoshioka-Tarver et al. 2012; Sun et al. 2016; Xu et al. 2017a, 2017b). It was also found that the vertical flame test gave a maximum damage length of $5 \mathrm{~cm}$ to $9.2 \mathrm{~cm}$ for the treated fabrics, while the non-treated fabrics burned completely. 
For the cotton treated with PGTES (add-on 25.2\%), Castellano et al. (2019) showed that the TGA char formation at $600{ }^{\circ} \mathrm{C}$, the $\left[\mathrm{CO}_{2}\right] /[\mathrm{CO}]$ ratio and the residue were $38 \%$ and 20 and $26 \%$, respectively, with a maximum char length of $5 \mathrm{~cm}$. For the control fabric, which burned completely within a very short time, these values were 5.8\%, 143, and 1\%, respectively (Table 1). For the cotton treated with DPTA, the LOI and the remaining TGA char at $600{ }^{\circ} \mathrm{C}$ of a pure cotton fabric, which burned entirely, increased to $25.4 \%$ and approximately $42 \%$ from $18.4 \%$ and approximately $15 \%$, respectively, with maximum damage length of $8.1 \mathrm{~cm}$ (Tables 1 and 2) (Zhao et al. 2017).

Cotton fabrics treated with $N, P$, and Cl-based non-polymeric organic compounds

A phosphorous trichloride ( $\left.\mathrm{PCl}_{3}\right)$-dimethylformamide (DMF) adduct was prepared according to a protocol described elsewhere by Smith (1966), as seen in Fig. 17. A cotton fabric was then treated with the prepared $\mathrm{PCl}_{3}-\mathrm{DMF}$ adduct to form a covalent link between cotton fabric and the adduct through $\mathrm{O}-\mathrm{P}$ and $\mathrm{O}-\mathrm{C}$ linkages resulting from the reaction of the $\mathrm{P}$ - and double-bonded $\mathrm{C}$ - sites of the adduct with hydroxyl groups of cellulose of the cotton fabric (Fig. 17) (Vigo et al. 1973).
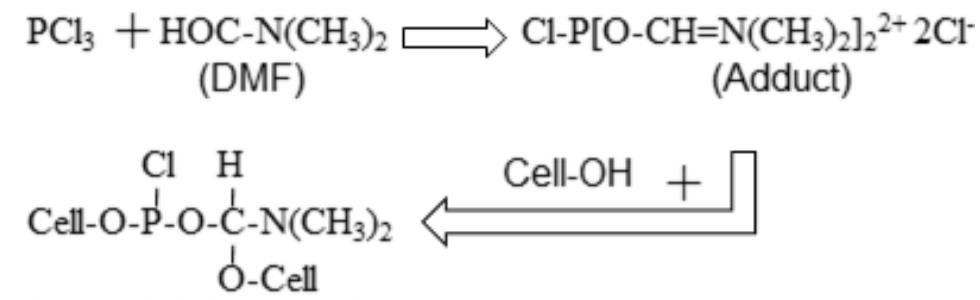

(Cotton fabric treated

with $\mathrm{PCl}_{3}$-DMF adduct)

Fig. 17. Chemical reactions for fabricating cotton fabric covalently linked with $\mathrm{PCl}_{3}-\mathrm{DMF}$ adduct (Smith 1966; Vigo et al. 1973)

Cotton fabrics that were treated with $5 \%$ adduct for 5 min exhibited flameretardancy. For a $30 \mathrm{~cm}$ original sample length, the char formation was $8.9 \mathrm{~cm}$ (Table 2) (Vigo et al. 1973). However, the entire length $(30 \mathrm{~cm})$ of the control fabric was burned quickly by the vertical flame without the formation of any char (Table 1). The incorporation of $\mathrm{PCl}_{3}$-DMF helped to achieve a good flame-retardancy of the treated cotton fabric.

Cotton fabrics treated with $\mathrm{N}, \mathrm{B}, \mathrm{Cl}$-based non-polymeric organic compounds

Tri-HTAC (2,4,6-tri[(2-hydroxy-3-trimethyl-ammonium)propyl]-1,3,5-triazine chloride) was added to boric acid $\left(\mathrm{H}_{3} \mathrm{BO}_{3}\right)$ and a cotton fabric, which resulted in a covalent bond between the cotton and the B-containing Tri-HTAC. The chemical reaction for this process is shown in Fig. 18.

The flame-retardant properties of the cotton produced this way were studied by Xie et al. (2013). It was found that the cotton fabric's resistance to fire increased due to the incorporation of the $\mathrm{N}, \mathrm{B}$, and $\mathrm{Cl}-$ based non-polymeric organic compound Tri-HTAC. The data is shown in Tables 1 and 2, which show that the LOI and the TGA char formation at $600{ }^{\circ} \mathrm{C}$ increased from approximately $22 \%$ to approximately $27.5 \%$ and from $6.3 \%$ to approximately $40.5 \%$, respectively, after incorporating B-containing Tri-HTAC in the cotton fabric. 


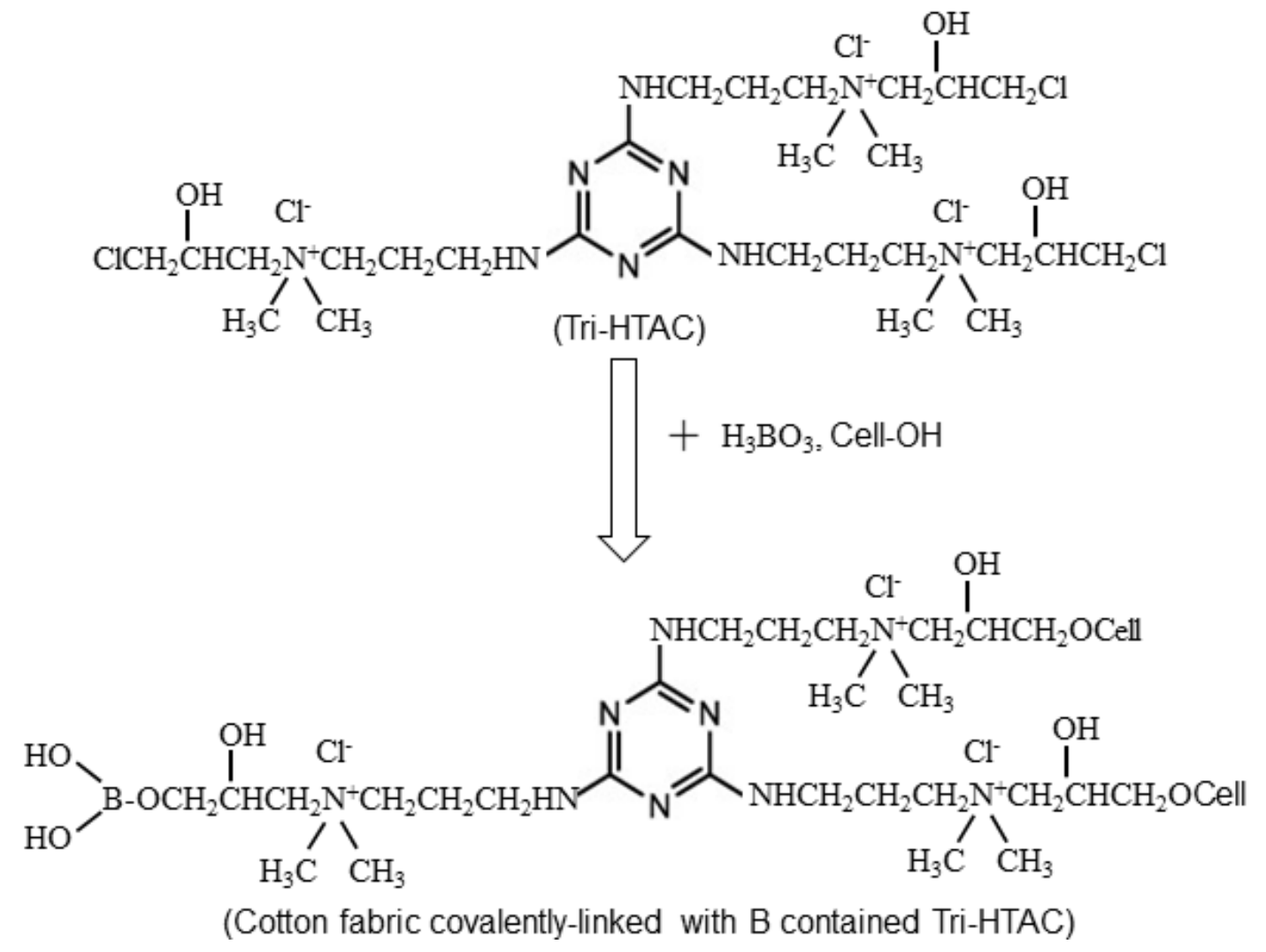

Fig. 18. Chemical reactions for fabricating cotton fabric covalently linked with B-containing TriHTAC (Xie et al. 2013)

\section{Cotton Fabrics Treated with Polymeric/Non-Polymeric Hybrid Organic Flame Retardants}

Polymeric/non-polymeric hybrid organic compounds that contain N, P, S, and CNT can work as flame-retardant materials for cellulosic textiles. These types of organic compounds can work as flame-retardants due to the presence of one or more types of these four categories of materials (N, P, S, and CNT). These materials can be added in their original organic form or they can be incorporated via chemical modification of cotton fabrics.

\section{Cotton Fabrics Treated with N, P-Based Polymeric/Non-Polymeric Hybrid Organic Flame-Retardant}

Layer-by-layer deposition on cotton of alternating cationic polyelectrolytes and anionic compounds can be used as a method to render cotton flame-retardant. Cotton with bilayers of cationic polyethylenimine (PEI) and anionic phytic acid (PA) was produced by Zhang et al. (2019b). The cotton was immersed in a PEI solution, removed from the solution, rinsed with water, and then dried at $80^{\circ} \mathrm{C}$. Subsequently, the fabric coated by the cationic PEI was dipped into a PA solution, taken out of the solution, rinsed with water, and then dried at $80^{\circ} \mathrm{C}$. After such a cycle, the cotton fabric was coated by one PEI/PA bilayer. This procedure was repeated eight times to obtain eight bilayers on the cotton fabric. The layer-by-layer process is shown schematically in Fig. 19. 


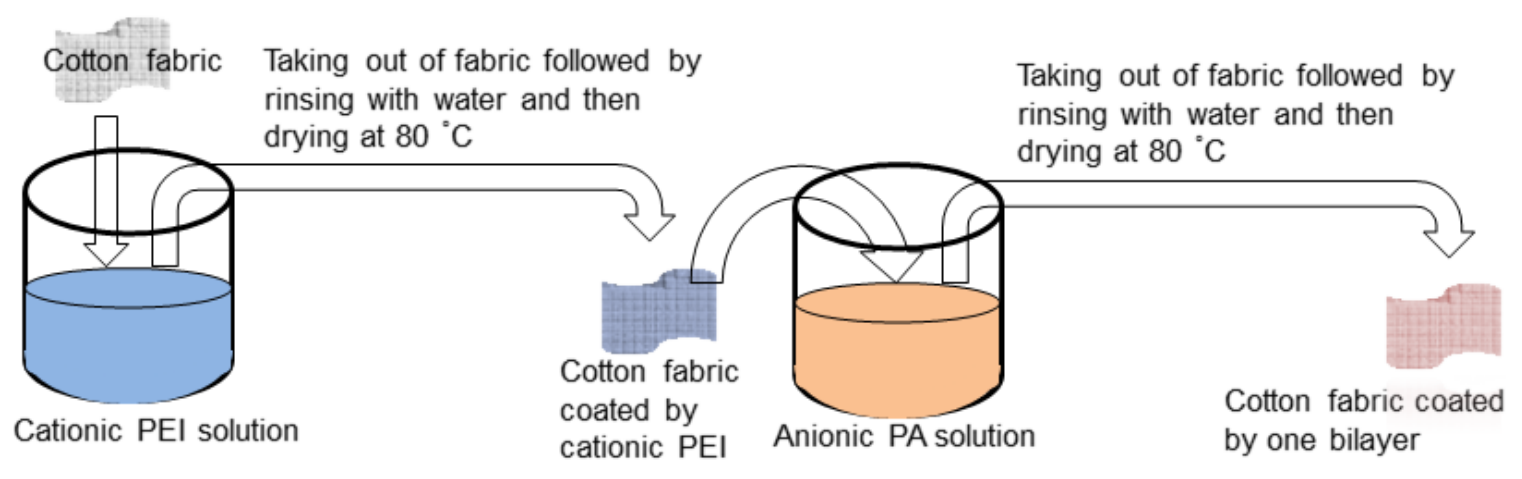

Fig. 19. Schematic representation of the fabrication of the cotton fabric coated by PEI/PA bilayers (Zhang et al. 2019b). Multilayers can be formed by repeating this process multiple times.

The cotton fabric coated by PEI/PA bilayers exhibited flame-retardant properties (Zhang et al. 2019b). The pure cotton fabric had an LOI of $18.5 \%$ and a TGA residue (at $600{ }^{\circ} \mathrm{C}$ ) of approximately $16.3 \%$, which increased to $37 \%$ and approximately $35 \%$, respectively, for the treated cotton fabric. A vertical flame produced a damage length of approximately $7 \mathrm{~cm}$ in the treated sample but burned the entire length of the non-treated cotton fabric (Tables 1 and 2).

\section{Cotton Fabrics Treated with N, P, S, and CNT-based Polymeric/Non- Polymeric Hybrid Organic Flame-Retardant}

Cotton with bilayers of cationic polyhexamethylene guanidine phosphate (PHMGP) and anionic VBL-CNT (fluorescent whitening agent (VBL)-carbon nanotube) was produced by Ding et al. (2016). The cotton fabric was dipped into a PHMGP solution, taken out of the solution, rinsed with water, and then dried at $60{ }^{\circ} \mathrm{C}$. Subsequently, the fabric coated by cationic PHMGP was dipped into anionic solution containing fluorescent whitening agent VBL (4,4'-bis[(hydroxyethylamino-6-anilino-1,3,5-triazin-2yl) amino] diphenylethylene-2,2'-sodium disulfonate) and carbon nanotubes (CNT), taken out of solution, rinsed with water, and then dried at $60{ }^{\circ} \mathrm{C}$. The cotton fabric was coated by one bilayer after this cycle. Ten cycles were performed to obtain 10 bilayers on the cotton fabric. The layer-by-layer process is similar to what is shown in Fig. 19. Testing the coated cotton showed that the flame-retardancy of the cotton fabric improved due to coating by the N, P, S, and CNT-based polymeric/non-polymeric hybrid organic, PHMGP/VBL-CNT (Ding et al. 2016). After making the coating, the fabric promptly self-extinguished after ignition, and the maximum damage length was approximately $15 \mathrm{~cm}$. However, the nontreated fabric burned completely within a very short time without the formation of any residue in the vertical flame tester (Tables 1 and 2). Moreover, the TGA char formation (at $600{ }^{\circ} \mathrm{C}$ ) for the treated fabric increased to $21.7 \%$ from $3.3 \%$ for the pure fabric (Tables 1 and 2).

\section{FLAME-RETARDANT COTTON FABRICS OBTAINED BY THE TREATMENT WITH INORGANIC FLAME-RETARDANTS}

An example of an inorganic flame-retardant is ammonium polyphosphate (APP), a P-based inorganic flame retardant, which was applied as a coating on cotton fabric to develop flame-retardancy (Yin et al. 2018; Lin et al. 2019). To produce the APP-coated 
cotton, a cotton fabric was dipped into an aqueous solution of APP and then dried at $80{ }^{\circ} \mathrm{C}$. The APP was attached to cellulose due to formation of hydrogen bonds between a hydrogen of a cellulose hydroxyl group and an oxygen of the polyphosphate group. A high number of - $\mathrm{OH}$ groups of cellulose chains can strongly interact with $\mathrm{N}-\mathrm{H}, \mathrm{P}=\mathrm{O}$ and $\mathrm{P}-\mathrm{O}$ groups in APP through hydrogen bond formation (Yin et al. 2018). A schematic representation of the fabrication of the cotton fabric coated by APP is shown in Fig. 20.

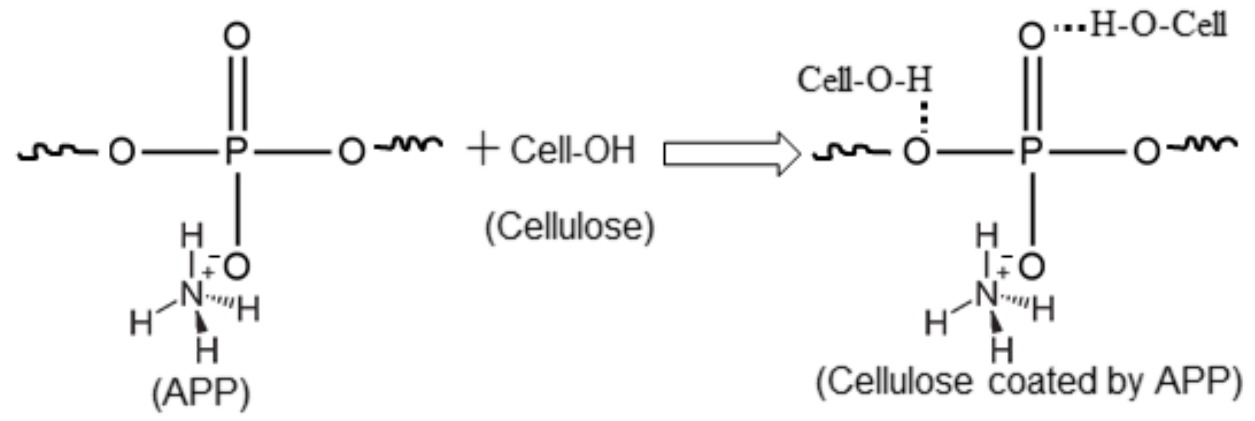

Fig. 20. Schematic representation on fabrication of cotton fabric coated by APP (Yin et al. 2018; Lin et al. 2019).

The flame retardant properties of APP-coated cotton, such as TGA char formation increased significantly and the damage length tested by the vertical flame tester decreased (Tables 1 and 2).

\section{FLAME-RETARDANT COTTON FABRICS OBTAINED BY THE TREATMENT WITH ORGANIC/INORGANIC HYBRID FLAME-RETARDANTS}

A multicomponent fire-retardant was developed by Lessan et al. (2011).

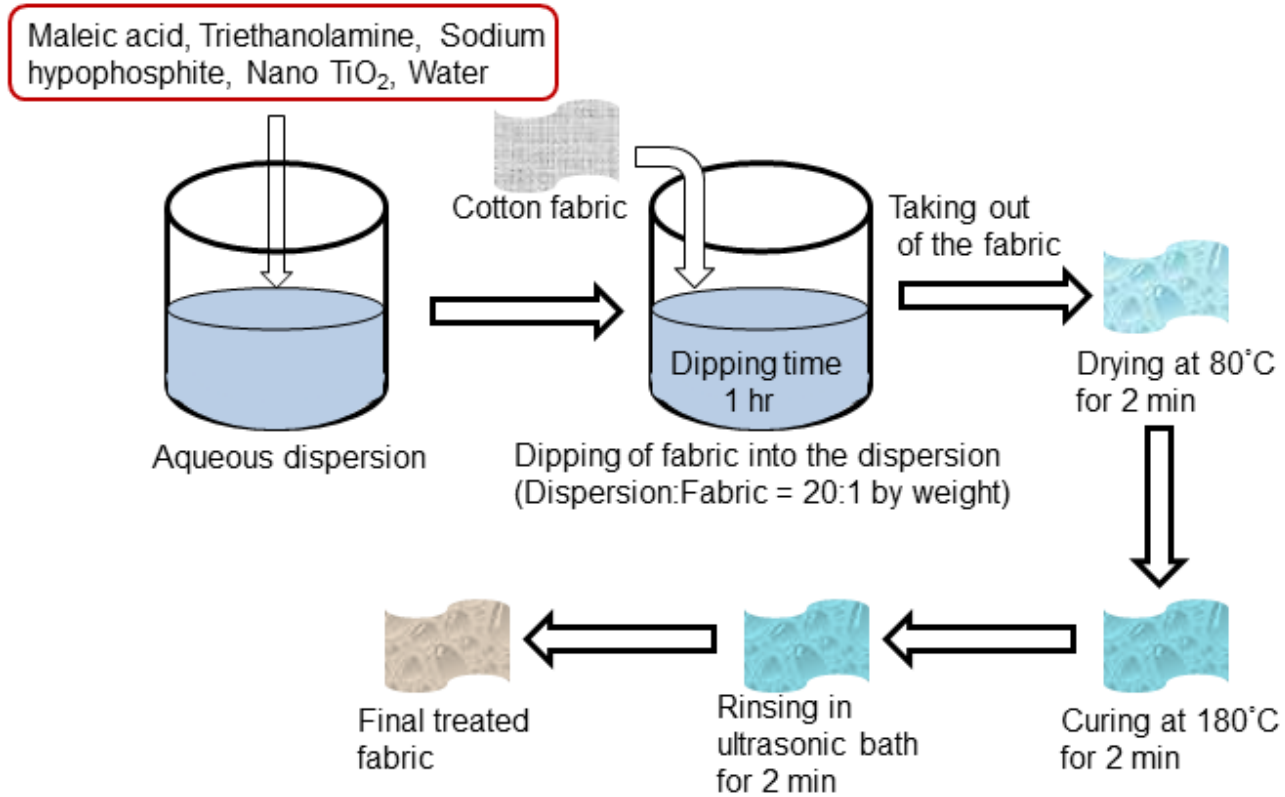

Fig. 21. Schematic representation of the cotton fabric treated with the aqueous dispersion of SHP, MA, TEA, and nano $\mathrm{TiO}_{2}$ (Lessan et al. 2011). 
An aqueous dispersion of sodium hypophosphite (SHP), maleic acid (MA), triethanol amine (TEA), and nano $\mathrm{TiO}_{2}$ was prepared in an ultrasonic bath (Merck Chemical Co. and Evonik Co., Germany). A cotton fabric was then impregnated in the dispersed solution for $1 \mathrm{~h}$. The weight ratio of dispersion to fabric was 20:1. The treated cotton fabric was taken out from the dispersed solution, dried at $80{ }^{\circ} \mathrm{C}$ for $2 \mathrm{~min}$, and then cured at $180{ }^{\circ} \mathrm{C}$ for $2 \mathrm{~min}$. The treated samples were rinsed in an ultrasonic bath for $5 \mathrm{~min}$ to remove non-attached nano $\mathrm{TiO}_{2}$ from the fabric surface (Lessan et al. 2011). The entire process is presented schematically in Fig. 21. The measured LOI and the residual char (Table 2) show that the treated cotton was flame-retardant.

Another example of a multicomponent flame-retardant consisted of polyphosphoric acid (PPA), PEI, and nanosilica. The cotton fabric was first immersed into an aqueous solution of PPA to produce a negatively charged phosphorylated cotton fabric, which was then immersed into an aqueous dispersion of nano $\mathrm{SiO}_{2}$ coated by PEI, to generate a flameretardant bilayer on the cotton fabric (Li et al. 2019). Cationic PEI wrapped nano $\mathrm{SiO}_{2}$ was produced from a $\mathrm{SiO}_{2}$-PEI solution, the $\mathrm{pH}$ of which was adjusted to five with acetic acid. The chemical reactions for making a PPA/PEI-SiO 2 coating on the cotton fabric are shown in Fig. 22.

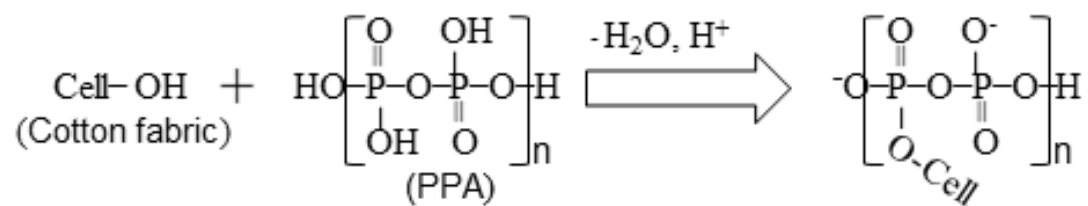

(Negatively charged phosphorylated cotton fabric)

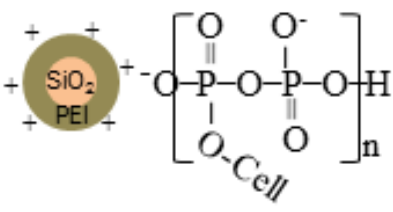

(Cotton fabric coated by PPA/PEI-SiO ${ }_{2}$ )

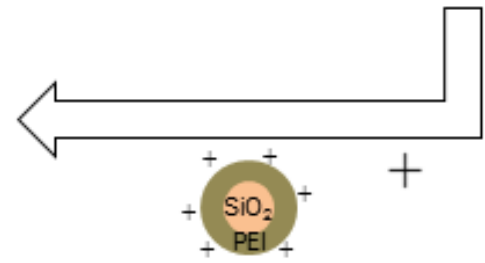

(Cationic PEl wrapped nano $\mathrm{SiO}_{2}$ )

Fig. 22. Chemical reactions for fabricating cotton fabric coated by the PPA/PEI-SiO 2 solution ( $\mathrm{Li}$ et al. 2019)

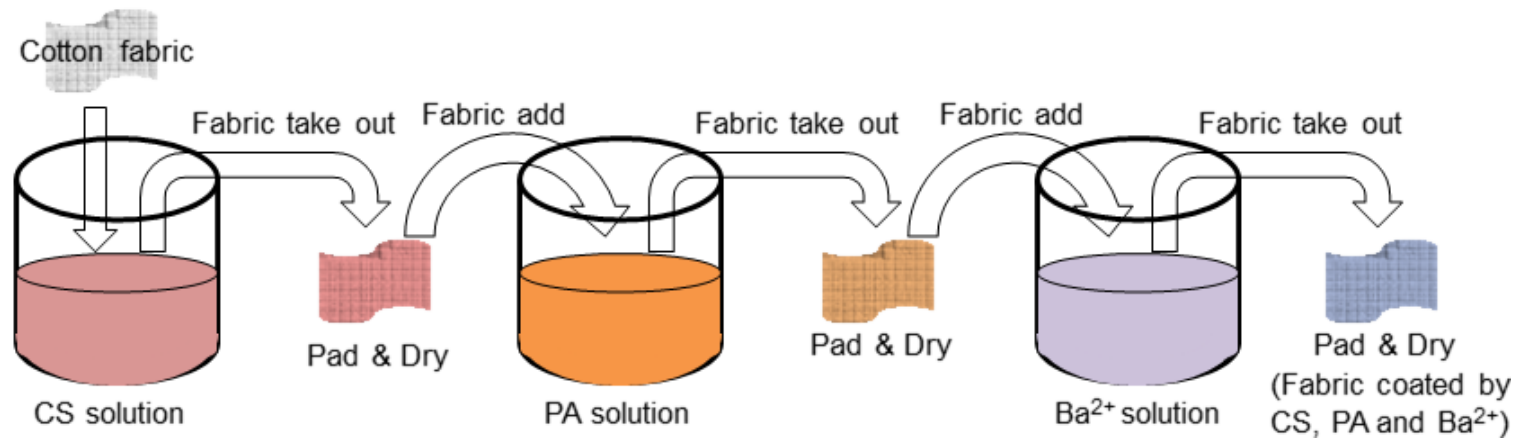

Fig. 23. Schematic representation on the fabrication of the cotton fabric coated by CA, PA, and $\mathrm{BA}^{2+}$ (Zhang et al. 2019a) 
Another multicomponent coating of cotton that was flame-retardant consisted of chitosan (CS), phytic acid (PA), and barium ions $\left(\mathrm{Ba}^{2+}\right)$. A cotton fabric was immersed into a CS solution for $5 \mathrm{~min}$ and then padded dry. This dried fabric was then immersed into a PA solution for $5 \mathrm{~min}$, followed again by padding and drying. Finally, this treated fabric was dipped into a $\mathrm{Ba}^{+2}$ solution for $5 \mathrm{~min}$, padded and dried to obtain a cotton fabric coated by CS, PA, and $\mathrm{Ba}^{2+}$ ions. A schematic representation of the process can be seen in Fig. 23 (Zhang et al. 2019a).

A dual component PA and silica solution coating has also been found to be a flameresistant, coating on cotton. A mixture consisting of tetraethyl orthosilicate (TEOS), ethanol and PA was employed to prepare a PA/silica solution in which a cotton fabric was immersed for a certain period. The impregnated cotton fabric was then taken out from the $\mathrm{PA} /$ silica solution, dried at $80{ }^{\circ} \mathrm{C}$, and cured at $160{ }^{\circ} \mathrm{C}$ for $3 \mathrm{~min}$. The treated cotton fabric was then washed and air-dried. The entire process for the fabrication of the cotton fabric coated by the PA/silica solution is shown exhibited schematically in Fig. 24.

Studies of the dual and multicomponent coatings on cotton, discussed above, showed that these coatings rendered cotton flame-retardant (Lessan et al. 2011; Li et al. 2019; Zhang et al. 2019a; Cheng et al. 2020). Each study showed that pure cotton fabric burned completely within a very short time without the formation of any residue. In contrast, the treated fabrics promptly self-extinguished after ignition, and the maximum damage length reduced remarkably in each case (Tables 1 and 2). The TGA char formation also increased for the treated fabrics in every case.

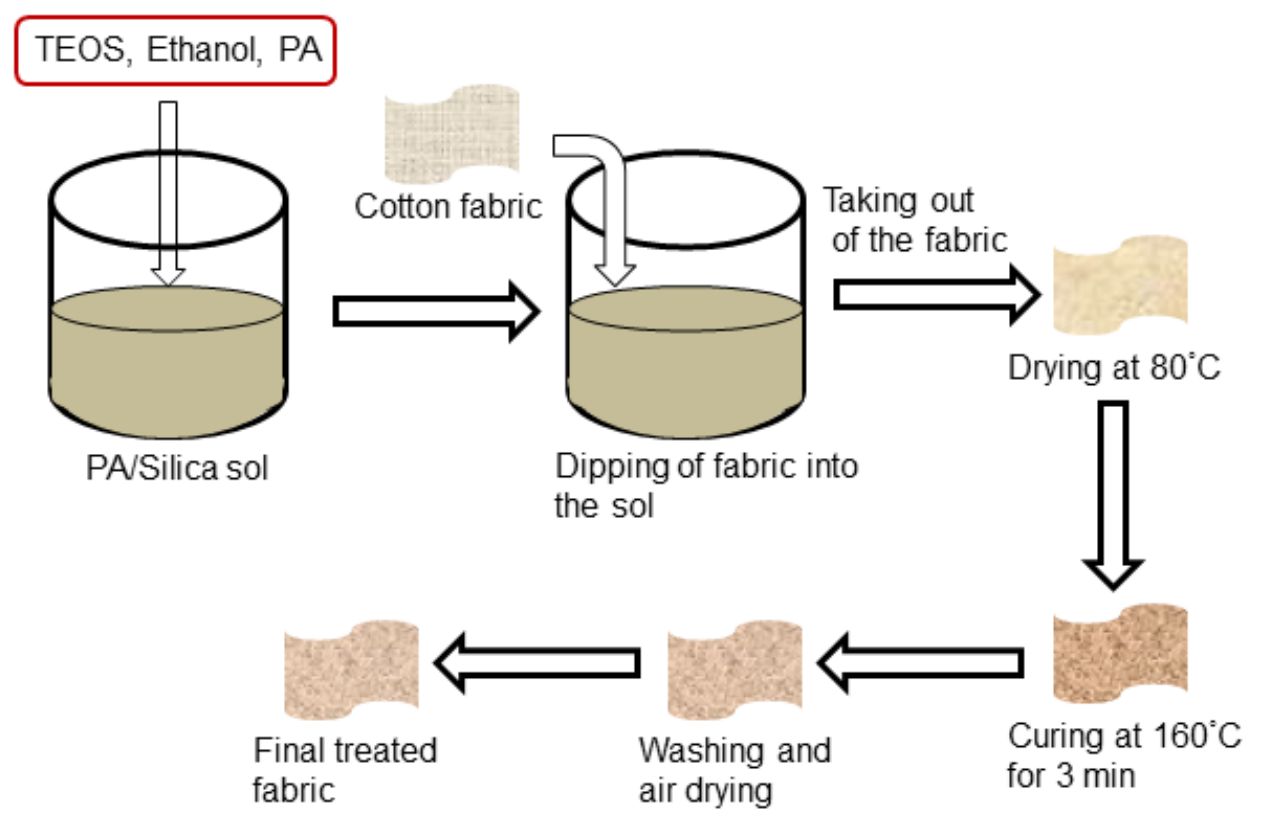

Fig. 24. Schematic representation on the fabrication of cotton fabric coated by the PA/silica solution (Cheng et al. 2020)

\section{COMPARISONS BETWEEN VARIOUS FLAME-RETARDANT COTTONS}

A major difficulty in comparing various flame-retardants is that in most studies the amount of flame-retardant incorporated in cotton varies tremendously. However, an apparent comparison can be made based on their reported compositions and performances. 
Table 2 summarizes the flame-retardant properties of cotton treated with flame-retardants, either adsorbed or covalently linked.

Table 2. Fire-resistant Properties of Textiles Fabricated from Cellulose Treated with Flame-retardants

\begin{tabular}{|c|c|c|c|c|c|c|c|}
\hline $\begin{array}{l}\text { Treated } \\
\text { Cotton } \\
\text { Textiles }\end{array}$ & $\begin{array}{l}\text { Add- } \\
\text { on (\%) }\end{array}$ & $\begin{array}{l}\mathrm{LOI} \\
(\%)\end{array}$ & $\begin{array}{l}\text { Char } \\
\text { length } \\
\text { (cm) }\end{array}$ & $\begin{array}{l}\text { Char } \\
\text { b (\%) }\end{array}$ & $\begin{array}{l}{\left[\mathrm{CO}_{2}\right] /} \\
{[\mathrm{CO}]^{\mathrm{c}}} \\
\text { Ratio }\end{array}$ & $\begin{array}{l}\text { Residue }^{c} \\
(\%)\end{array}$ & References \\
\hline \multicolumn{8}{|l|}{$\begin{array}{l}\text { Adsorbed } \\
\text { Flame } \\
\text { Retardants }\end{array}$} \\
\hline PAMAM & 19 & - & 2.3 & $\sim 30$ & $\sim 9$ & - & Manfredi et al. 2018a \\
\hline SS-PAMAM & 12 & - & 0.7 & 24 & 30.8 & 5.5 & $\begin{array}{l}\text { Emilitri et al. 2007; } \\
\text { Manfredi et al. 2018b }\end{array}$ \\
\hline HBPOPN & 28.1 & 42 & 5.6 & $\sim 35$ & 3.1 & - & Ling and Guo 2020 \\
\hline ATEPAHP & 26 & 40.5 & 4.8 & $\sim 45$ & 29 & 41.7 & Tian et al. 2019 \\
\hline ACMPEP & 25 & 40.1 & 3.8 & $\sim 42$ & 29.2 & 25 & Li et al. 2019 \\
\hline AATMP & 14.3 & 43.9 & 3.0 & 20.2 & - & 31.6 & Huang et al. 2019 \\
\hline AMHMPA & 25.3 & 37.5 & 5.3 & $\sim 40$ & $\sim 56.6$ & 14.3 & Zhang et al. 2018a \\
\hline PGPTES & 25.2 & - & 5 & 38 & 20 & 26 & Castellano et al. 2019 \\
\hline $\mathrm{PCl}_{3}-\mathrm{DMF}$ & 5 & - & 8.9 & - & - & - & Vigo et al. 1973 \\
\hline PEl/PA & 24.2 & 37 & $\sim 7$ & $\sim 35$ & - & - & Zhang et al. 2019b \\
\hline $\begin{array}{l}\text { PHMGP/VBL } \\
\text {-CNT }\end{array}$ & 11.3 & - & $\sim 15$ & 21.7 & - & - & Ding et al. 2016 \\
\hline APP & - & - & $\sim 28$ & $\sim 40$ & - & - & $\begin{array}{l}\text { Yin et al. 2018; Lin et } \\
\text { al. } 2019\end{array}$ \\
\hline $\begin{array}{l}\text { SHP, MA, } \\
\text { TEA, and } \\
\text { nano } \mathrm{TiO}_{2}\end{array}$ & - & 22.7 & 0.7 & 27 & - & - & Lessan et al. 2011 \\
\hline $\begin{array}{l}\mathrm{PPA} / \mathrm{PEI}- \\
\mathrm{SiO}_{2}\end{array}$ & 23.4 & 29.6 & 10.4 & 44 & - & - & Li et al. 2019 \\
\hline $\begin{array}{l}\mathrm{CS}, \mathrm{PA} \text {, and } \\
\mathrm{Ba}^{2+} \text { ions }\end{array}$ & 5.2 & 22 & 1.4 & 29.4 & - & 29.7 & Zhang et al. 2019a \\
\hline PA/Silica sol. & - & 29.8 & 3.2 & - & - & - & Cheng et al. 2020 \\
\hline \multicolumn{8}{|l|}{$\begin{array}{l}\text { Covalently- } \\
\text { linked } \\
\text { Polymers }\end{array}$} \\
\hline $\begin{array}{l}\text { G2-PAMAM } \\
\text { Through CA }\end{array}$ & - & $\sim 23$ & 0.32 & 25.1 & - & - & $\begin{array}{l}\text { Taherkhani and } \\
\text { Hasanzadeh } 2018\end{array}$ \\
\hline AHEDPA & 20.1 & 41.5 & 5.3 & $\sim 45$ & 3.8 & 38.9 & Lu et al. 2018 \\
\hline APA & 14.5 & 36.1 & 3.5 & $\sim 40$ & 3.1 & 36.2 & Feng et al. 2017 \\
\hline AEDTMPA & 8 & 43.6 & 3.5 & 43.4 & 2.1 & 42.5 & Zheng et al. 2016 \\
\hline ATPMPA & 26.1 & 43.6 & 2.5 & 38 & 28.5 & 30.8 & Wan et al. 2019 \\
\hline DHTP & $\begin{array}{l}28.1- \\
30.7\end{array}$ & $\begin{array}{c}26.1- \\
34\end{array}$ & $5-9.2$ & $\begin{array}{c}31.2- \\
43\end{array}$ & - & - & $\begin{array}{l}\text { Yoshioka-Tarver et } \\
\text { al. 2012; Sun et al. } \\
\text { 2016; Xu et al. } \\
\text { 2017a, 2017b }\end{array}$ \\
\hline DPTA & 29.3 & 25.4 & 8.1 & $\sim 42$ & - & - & Zhao et al. 2017 \\
\hline $\begin{array}{l}\text { B Containing } \\
\text { Tri-HTAC }\end{array}$ & 8 & $\sim 27.5$ & - & $\tilde{40.5}$ & - & - & Xie et al. 2013 \\
\hline
\end{tabular}

${ }^{a}$ Obtained from vertical flame test of $30 \mathrm{~cm}$ long samples; ${ }^{\mathrm{b}}$ at $600{ }^{\circ} \mathrm{C}$, from TGA; ${ }^{\mathrm{c}}$ from cone calorimetry 
This review has shown that textiles that had been prepared with P-based nonpolymeric flame retardants, such as AHEDPA and APA (Feng et al. 2017; Lu et al. 2018), demonstrated the best performances among all the different types of flame-retardants. Phosphorus-based flame-retardants are quite versatile in their flame-retardant action, in which both the condensed and the gas phase play a role in the efficiency of the flameretardant (Granzow 1978; Li et al. 2005; Salmeia et al. 2016; Liang et al. 2017). The inclusion of flame-retardants accelerates the formation of a dense char layer to promote the dehydration and carbonization of the cotton fabric. The formation of a char layer also prevents heat radiation and oxygen transfer that also has a positive effect on the flameretardancy of the treated fabric.

\section{SUMMARY AND CONCLUDING REMARKS}

There are two methods for fabricating cotton-based flame-retardant textiles: coating and covalently-linking flame-retardants. It has been shown that textiles coated by N-based PAMAM, N-S-based SS-PAMAM, N-P-Si-based PGPTES, N-P-based PEI/PA blends, APP-N-P-S-CNT-based PHMGP/VBL/CNT blends, P-N-TiO 2 -based SHP/MA/ TEA/nanoTiO 2 blends, P-N-Si-based PPA/PEI/SiO 2 blends, N-P-Ba ${ }^{2+}$-based CS/PA/Ba ${ }^{2+}$ blends, and $\mathrm{P}-\mathrm{SiO}_{2}$-based $\mathrm{PA} /$ silica gels, all have considerable flame-retardancy. The flame-retardancy of textiles was also achieved by a covalent-linkage between the cotton fabric and each of the following materials: N-based G2-PAMAM, P-based HBPOPN, AHEDPA and APA, N-P-based AEDTMPA, ATPMPA, ATEPAHP, ACMPEP, AATMP and AMHMPA, N-P-Si-based DPTA and DHTP, N-P-Cl-based $\mathrm{PCl}_{3}$-DMF adduct, and NB-Cl-based B-containing tri-HTAC. It is not easy to compare the flame-retardant ability of the textiles prepared by different methods because in most cases, different amounts of flame-retardant material were incorporated into cotton textiles, which were obtained from different sources. However, it was evident that flame-retardant properties of cotton textiles were developed due to the incorporation of the above materials.

This work clearly outlines the wide potentialities of cotton-based flame-retardant textiles fabricated with the use of the flame-retardant materials mentioned above. The materials mentioned above could also be applied to other cellulose-based textiles to make them flame retardant. The concurrent presence of phosphorus and other elements including nitrogen, sulphur, boron, chlorine, barium, and nanomaterials (CNT, silica, and $\mathrm{TiO}_{2}$ ) could be significant in order to obtain synergistic effects during the exposure of the treated textiles to a flame or to a heat source.

A sustainable flame-retardant textile should also demonstrate durability to washing, which has not been achieved for many of the flame-retardant textiles mentioned above (Xu et al. 2017a; Lu et al. 2018; Taherkhani and Hasanzadeh 2018; Zhang et al. 2019a). Some exhibit no washing fastness at all, and some can withstand a very limited number of washing cycles before losing their flame-retardant properties. This is obviously a drawback of the currently reported cotton-based flame-retardant textiles, which use is restricted to applications for which longevity to washing is not required. For this reason, further research is needed to fabricate novel and effective cotton-based flame-retardant textiles that can overcome this drawback. In general, an excellent washing fastness is achieved for the flame-retardant textiles in which covalent bonds are formed between textiles and flameretardants. During washing, small adsorbed molecules can be washed out easily, whereas adsorbed polymeric compounds remain adsorbed due to multiple linkage with the textiles.

Islam \& van de Ven (2021). "Flame-retardant textile," BioResources 16(2), 4354-4381.

4376 
Adsorbed flame-retardants can be washed out during washing, but even cottons with covalently linked flame-retardants loose some of their flame-retardancy during washing, as in each washing cycle part of the cotton ends up in the wastewater. For synthetic textiles, this is the main source of microplastics in municipal waste waters. Flame-retardants are dominantly located on the surface of fibers (Lessan et al. 2011; Li et al. 2019; Zhang et al. 2019 a, b; Cheng et al. 2020), and thus cotton fibrils removed during washing are expected to have a higher concentration of flame-retardants than the washed material.

Although flame-retardants protect textiles against ignition, they could adversely affect the environment and human health when used above a certain limit. Flame-retardants can be released to the environment and the human body during fabrication and after disposing of the flame-retardant textiles. The flame-retardants can contaminate air, water and soil, and also can affect immune, reproductive, and nervous systems of human beings. Long-term exposure to flame-retardants can even cause cancer in humans (Segev et al. 2009).

\section{ACKNOWLEDGEMENTS}

The authors want to acknowledge financial support from a NSERC Strategic Research Project grant (Grant No. 506303-17) and the industrial partner FPInnovations.

\section{REFERENCES CITED}

ASTM D2863-19 (2019). "Standard test method for measuring the minimum oxygen concentration to support candle-like combustion of plastics (oxygen index)," ASTM International, West Conshohocken, PA.

ASTM D6413 (2015). "Standard test method for flame resistance of textiles (vertical test)," ASTM International, West Conshohocken, PA.

Babu, K., Rendén, G., Mensah, R. A., Kim, N. K., Jiang, L., Xu, Q., Restás, A., Neisiany, R. E., Hedenqvist, M. S., Försth, et al. (2020). "A review on the flammability properties of carbon-based polymeric composites: State-of-the-art and future trends," Polymers 12(7), 1518. DOI: 10.3390/polym12071518

Beyler, C., Croce P., Dubay, C., Johnson, P., and McNamee, M. (2017). “Oxygen consumption calorimetry, William Parker: 2016 DiNenno Prize," Fire Science Review 6(1). DOI: 10.1186/s40038-016-0016-z

Carmichael, A. (2014). "Man-made fibers continue to grow," in: 2014 Textile World Innovation Forum, Atlanta, GA.

Castellano, A., Colleoni, C., Iacono, G., Mezzi, A., Plutino, M. R., Malucelli, G., and Rosace, G. (2019). "Synthesis and characterization of a phosphorous/nitrogen based sol-gel coating as a novel halogen- and formaldehyde-free flame retardant finishing for cotton fabric," Polymer Degradation and Stability 162, 148-159. DOI: 10.1016/j.polymdegradstab.2019.02.006

Coats, A. W., and Redfern, J. P. (1963). "Thermogravimetric analysis: A review," Analyst 88(1053), 906-924. DOI: 10.1039/an9638800906

Cheng, X.-W., Tang, R.-C., Guan, J.-P., and Zhou, S.-Q. (2020). "An eco-friendly and effective flame retardant coating for cotton fabric based on phytic acid doped silica 
sol approach," Progress in Organic Coatings 141, 105539. DOI:

10.1016/j.porgcoat.2020.105539

Dai, K., Deng, Z., Liu, G., Wu, Y., Xu, W., and Hu, Y. (2020). "Effects of a reactive phosphorus-sulfur containing flame-retardant monomer on the flame retardancy and thermal and mechanical properties of unsaturated polyester resin," Polymers 12(7), 1441. DOI: $10.3390 /$ polym12071441

Ding, X., Fang, F., Du, T., Zheng, K., Chen, L., Tian, X., and Zhang, X. (2016). "Carbon nanotube-filled intumescent multilayer nanocoating on cotton fabric for enhancing flame retardant property," Surface and Coatings Technology 305, 184-191. DOI: 10.1016/j.surfcoat.2016.08.035

Emilitri, E., Ferruti, P., Annunziata, R., Ranucci, E., Rossi, M., Falciola, L., Mussini, P., Chiellini, F., and Bartoli, C. (2007). "Novel amphoteric cystine-based poly(amidoamine)s responsive to redox stimuli," Macromolecules 40(14), 4785-4793. DOI: $10.1021 / \mathrm{ma062115e}$

Feng, Y., Zhou, Y., Li, D., He, S., Zhang, F., and Zhang, G. (2017). “A plant-based reactive ammonium phytate for use as a flame-retardant for cotton fabric," Carbohydrate Polymers 175, 636-644. DOI: 10.1016/j.carbpol.2017.06.129

Gaan, S., Salimova, V., Rupper, P., Ritter, A., and Schmid, H. (2011). "Flame retardant functional textiles," in: Functional Textiles for Improved Performance, Protection and Health, N. Pan and G. Sun (eds.), Woodhead Publishing, Sawston, UK, pp. 98130.

Granzow, A. (1978). "Flame retardation by phosphorus compounds," Accounts of Chemical Research 11(5), 177-183. DOI: 10.1021/ar50125a001

Holdsworth, A. F., Horrocks, A. R., and Kandola, B. K. (2020). "Potential synergism between novel metal complexes and polymeric brominated flame retardants in polyamide 6.6," Polymers 12(7), 1543. DOI: 10.3390/polym12071543

Horrocks, A. R., Kandola, B. K., Davies, P. J., Zhang, S., and Padbury, S. A. (2005). "Developments in flame retardant textiles - A review," Polymer Degradation and Stability 88(1), 3-12. DOI: 10.1016/j.polymdegradstab.2003.10.024

Horrocks, A. R., Tunc, M., and Price, D. (1988). "The burning behaviour of textiles and its assessment by oxygen-index methods," Textile Progress 18(1-3), 1-186. DOI: $10.1080 / 00405168908689004$

Horrocks, A. R. (2013). "Flame resistant textiles for transport applications," in: Handbook of Fire Resistant Textiles, Woodhead Publishing, Sawston, UK, pp. 603-622.

Huang, S., Feng, Y., Li, S., Zhou, Y., Zhang, F., and Zhang, G. (2019). "A novel high whiteness flame retardant for cotton," Polymer Degradation and Stability 164, 157 166. DOI: 10.1016/j.polymdegradstab.2019.03.014

ISO 4589 (2017). "Plastics - Determination of burning behaviour by oxygen index," International Organization for Standardization, Geneva, Switzerland.

Kundu, C. K., Li, Z., Song, L., and Hu, Y. (2020). “An overview of fire retardant treatments for synthetic textiles: From traditional approaches to recent applications," European Polymer Journal 137, 109911. DOI: 10.1016/j.eurpolymj.2020.109911

Lessan, F., Montazer, M., and Moghadam, M. B. (2011). "A novel durable flameretardant cotton fabric using sodium hypophosphite, nano $\mathrm{TiO}_{2}$ and maleic acid," Thermochimica Acta 520(1-2), 48-54. DOI: 10.1016/j.tca.2011.03.012

Liang, T., Jiang, Z., Wang, C., and Liu, J. (2017). "A facile one-step synthesis of flame retardant coatings on cotton fabric via ultrasound irradiation," Journal of Applied Polymer Science 134(30), 45114. DOI: 10.1002/APP.45114 
Ling, C., and Guo, L. (2020). "Preparation of a flame-retardant coating based on solventfree synthesis with high efficiency and durability on cotton fabric," Carbohydrate Polymers 230, 115648. DOI: 10.1016/j.carbpol.2019.115648

Li, S., Zhong, L., Huang, S., Wang, D., Zhang, F., and Zhang, G. (2019). “A novel flame retardant with reactive ammonium phosphate groups and polymerizing ability for preparing durable flame retardant and stiff cotton fabric," Polymer Degradation and Stability 164, 145-156. DOI: 10.1016/j.polymdegradstab.2019.04.009

Li, S., Lin, X., Li, Z., and Ren, X. (2019). "Hybrid organic-inorganic hydrophobic and intumescent flame-retardant coating for cotton fabrics," Composites Communications 14, 15-20. DOI: 10.1016/j.coco.2019.05.005

Li, Q., Jiang, P., Su, Z., Wei, P., Wang, G., and Tang, X. (2005). "Synergistic effect of phosphorus, nitrogen, and silicon on flame-retardant properties and char yield in polypropylene," Journal of Applied Polymer Science 96(3), 854-860. DOI: 10.1002/app.21522

Lin, D., Zeng, X., Li, H., Lai, X., and Wu, T. (2019). "One-pot fabrication of superhydrophobic and flame-retardant coatings on cotton fabrics via sol-gel reaction," Journal of Colloid and Interface Science 533, 198-206. DOI: 10.1016/j.jcis.2018.08.060

Liu, X., and Yu, W. (2005). "Evaluating the thermal stability of high performance fibers by TGA," Journal of Applied Polymer Science 99(3), 937-944. DOI: 10.1002/app.22305

Lu, Y., Jia, Y., Zhou, Y., Zou, J., Zhang, G., and Zhang, F. (2018). "Straightforward onestep solvent-free synthesis of the flame retardant for cotton with excellent efficiency and durability," Carbohydrate Polymers 201, 438-445. DOI: 10.1016/j.carbpol.2018.08.078

Lyon, R. E., Walters, R. N., Stoliarov S. I., and Safronava, N. (2013). Principles and Practices of Microscale Combustion Calorimetry (Report No. DOT/FAA/TC-12/53), U. S. Department of Transportation, Federal Aviation Administration, Atlantic City International Airport, NJ.

Manfredi, A., Carosio, F., Ferruti, P., Ranucci, E., and Alongi, J. (2018a). "Linear polyamidoamines as novel biocompatible phosphorus-free surface-confined intumescent flame retardants for cotton fabrics," Polymer Degradation and Stability 151, 52-64. DOI: 10.1016/j.polymdegradstab.2018.02.020

Manfredi, A., Carosio, F., Ferruti, P., Alongi, J., and Ranucci, E. (2018b). "Disulfidecontaining polyamidoamines with remarkable flame retardant activity for cotton fabrics," Polymer Degradation and Stability 156, 1-13. DOI: 10.1016/j.polymdegradstab.2018.07.028

Salmeia, K. A., Gaan, S., and Malucelli, G. (2016). "Recent advances for flame retardancy of textiles based on phosphorus chemistry," Polymers 8(9), 319. DOI: 10.3390/polym8090319

Segev, O., Kushmaro, A., and Brenner, A. (2009). "Environmental impact of flame retardants (persistence and biodegradability)," International Journal of Environmental Research and Public Health 6(2), 478-491.

Smith, T. D. (1966). "The reaction of N, N-dimethylformamide with phosphorus trichloride," Journal of the Chemical Society A 7, 841-842.

Sun, D., Wang, W., and Yu, D. (2016). "Preparation of fluorine-free water repellent finishing via thiol-ene click reaction on cotton fabrics," Materials Letters 185, 514518. DOI: 10.1016/j.matlet.2016.09.042 
Taherkhani, A., and Hasanzadeh, M. (2018). "Durable flame retardant finishing of cotton fabrics with poly(amidoamine) dendrimer using citric acid," Materials Chemistry and Physics 219, 425-432. DOI: 10.1016/j.matchemphys.2018.08.058

Tata, J., Alongi, J., Carosio, F., and Frache, A. (2011). "Optimization of the procedure to burn textile fabrics by cone calorimeter: Part I. Combustion behavior of polyester," Fire and Materials 35(6), 397-409. DOI: 10.1002/fam.1061

Tata, J., Alongi, J., and Frache, A. (2012). "Optimization of the procedure to burn textile fabrics by cone calorimeter: Part II. Results and discussion on nanoparticle-finished polyester," Fire and Materials 36(7), 527-536. DOI: 10.1002/fam.1105

Thi, H. N., Hong, K. V. T., Ha, T. N., and Phan, D.-N. (2020). "Application of plasma activation in flame-retardant treatment for cotton fabric," Polymers 12(7), 1575. DOI: 10.3390/polym 12071575

Tian, P., Lu, Y., Wang, D., Zhang, G., and Zhang, F. (2019). "Synthesis of a new N-P durable flame retardant for cotton fabrics," Polymer Degradation and Stability 165, 220-228. DOI: 10.1016/j.polymdegradstab.2019.04.024

Vigo, T. L., Collins, A. M., and Welch, C. M. (1973). "Flame-retardant cotton fabrics by reaction of cellulose with phosphorus trichloride-DMF adduct," Journal of Applied Polymer Science 17(2), 571-584. DOI: 10.1002/app.1973.070170220

Walters, R. N., Safronava, N., and Lyon, R. E. (2015). "A microscale combustion calorimeter study of gas phase combustion of polymers," Combustion and Flame 162(3), 855-863. DOI: 10.1016/j.combustflame.2014.08.008

Wan, C., Tian, P., Liu, M., Zhang, G., and Zhang, F. (2019). "Synthesis of a phosphorus-nitrogen flame retardant endowing cotton with high whiteness and washability," Industrial Crops and Products 141, 11738. DOI: 10.1016/j.indcrop.2019.111738

Weil, E. D. (1974). “Hexahydrotriazine phosphonate derivatives,” U. S. Patent No. 3849409.

Weil, E. D. (1975). "Process of flame retarding substrate by applying hexahydratriazine phosphonate derivatives," U. S. Patent No. 39056136.

Xie, K., Gao, A., and Zhang, Y. (2013). "Flame retardant finishing of cotton fabric based on synergistic compounds containing boron and nitrogen," Carbohydrate Polymers 98(1), 706-710. DOI: 10.1016/j.carbpol.2013.06.014

$\mathrm{Xu}, \mathrm{L}$. , Wang, W., and Yu, D. (2017a). "Durable flame retardant finishing of cotton fabrics with halogen-free organophosphonate by UV photoinitiated thiol-ene click chemistry," Carbohydrate Polymers 172, 275-283. DOI: 10.1016/j.carbpol.2017.05.054

$\mathrm{Xu}, \mathrm{L}$., Wang, W., and Yu, D. (2017b). "Preparation of a reactive flame retardant and its finishing on cotton fabrics based on click chemistry," RSC Advances 7(4), 2044-2050. DOI: $10.1039 / \mathrm{C} 6 \mathrm{RA} 26075 \mathrm{~F}$

Yin, W., Chen, L., Lu, F., Song, P., Dai, J., and Meng, L. (2018). "Mechanically robust, flame-retardant poly(lactic acid) biocomposites via combining cellulose nanofibers and ammonium polyphosphate," ACS Omega 3, 5615-5626. DOI: 10.1021/acsomega.8b00540

Yin, S., Ren, X., Lian, P., Zhu, Y., and Mei, Y. (2020). "Synergistic effects of black phosphorus/boron nitride nanosheets on enhancing the flame-retardant properties of waterborne polyurethane and its flame-retardant mechanism," Polymers 12(7), 1487. DOI: $10.3390 /$ polym 12071487 
Yoshioka-Tarver, M., Condon, B. D., Cintrón, M. S., Chang, S., Easson, M. W., Fortier. C. A., Madison, C. A., Bland, J. M., and Thach-Mien, D. Nguyen T.-M. D. (2012).

"Enhanced flame-retardant property of fiber reactive halogen-free organophosphonate," Industrial \& Engineering Chemistry Research 51(34), 1103111037. DOI: $10.1021 /$ ie300964g

Yusuf, M. A. (2018). "Review on flame retardant textile finishing: Current and future trends," Current Smart Materials 3(2), 99-108. DOI: $10.2174 / 2405465803666180703110858$

Zhang, F., Gao, W., Jia, Y., Lu, Y., and Zhang, G. (2018a). “A concise water-solvent synthesis of highly effective, durable, and eco-friendly flame-retardant coating on cotton fabrics," Carbohydrate Polymers 199, 256-265. DOI: 10.1016/j.carbpol.2018.05.085

Zhang, X.-S., Xia, Y.-Z., Shi, M.-W., and Yan, X. (2018b). "The flame retardancy of alginate/flame retardant viscose fibers investigated by vertical burning test and cone calorimeter," Chinese Chemical Letters 29(3), 489-492. DOI: 10.1016/j.cclet.2017.07.023

Zhang, Z., Ma, Z., Leng, Q., and Wang, Y. (2019a). "Eco-friendly flame retardant coating deposited on cotton fabrics from bio-based chitosan, phytic acid and divalent metal ions," International Journal of Biological Macromolecules 140, 303-310. DOI: 10.1016/j.ijbiomac.2019.08.049

Zhang, Y., Tian, W., Liu, L., Cheng, W., Wang, W., Liew K. M., Wang, B., and Hu, Y. (2019b). "Eco-friendly flame retardant and electromagnetic interference shielding cotton fabrics with multi-layered coatings," Chemical Engineering Journal 372, 1077-1090. DOI: 10.1016/j.cej.2019.05.012

Zhao, P., Xiong, K.,Wang, W., and Liu, Y. (2017). "Preparation of a halogen-free P/N/Si flame retardant monomer with reactive siloxy groups and its application in cotton fabrics," Chinese Journal of Chemical Engineering 25(9), 1322-1328. DOI: 10.1016/j.cjche.2016.09.015

Zheng, D., Zhou, J., Zhong, L., Zhang, F., and Zhang, G. (2016). "A novel durable and high-phosphorous-containing flame retardant for cotton fabrics," Cellulose 23, 22112220. DOI: 10.1007/s10570-016-0949-3

Article submitted: September 24, 2020; Peer review completed: January 30, 2021;

Revised version received and accepted: February 22, 2021; Published: March 1, 2021.

DOI: 10.15376/biores.16.2.Islam 